\title{
De la construcción del patrimonio gastronómico
}

\section{Gabriela Benavides de Rivero}

\section{Introducción}

Hasta el dia de hoy no existe en el Perú un concepto moderno de patrimonio gastronómico como producto de la evolución de criterios tradicionales hacia una visión crítica y razonable, capaz de responder a inquietudes como las siguientes: ¿Es posible hablar de un patrimonio gastronómico peruano o es que acasc existen varios patrimonios de acuerdo con la identidad que se tenga a partir de ellos, y, por el contrario, el alimento y las maneras de comer son elementos de distinción entre colectivos culturales y grupos sociales? ¿Existe una identificación con lo que no se conoce o, peor aún, con lo que se conoce mal? ¿Está la población peruana preparada para entender lo que significa patrimonio cultural gastronómico? ¿Interesa a los agentes culturales que ello se dé, o toda la discusión actual sobre este tema existe en tanto gire alrededor del negocio turístico? ¿Desde cuándo se habla de patrimonio gastronómico en el Perú y qué se ha hecho por su investigación, preservación, conservación y puesta en valor? ¿Quién decide lo que es patrimonio gastronómico y cómo se integran los aspectos de la cultura en la noción de patrimonio gastronómico?'

\footnotetext{
1 La actual discusión teórica en tomo del concepto de sociedad posimoderna y "conciencia fragmentada" concierne al argumento que se desarrollará en estas páginas en el sentido de la construcción de un concepto de patrimonio gastronómico que, a partir de elementos de identidad y distinción, derive de algún tipo de vinculo con la memoria colectiva. Por otro lado, el fenómeno luristico ha permitido que este tema sea compartido por un público cada vez mayor y mejor.
}

Lo que se quiere desarrollar en esta oportunidad descansa en tres instancias que buscan señalar, en primer lugar, si es posible o no hablar de un único patrimonio gastronómico para el Perú, es decir, si se ha construido, a pesar de los desencuentros y enfrentamientos políticos, sociales e ideológicos, un patrimonio cultural gastronómico que permita una identificación con la nación, más allá de las diferencias históricas y presentes. En segundo lugar, en qué niveles y con qué mecanismos se han manejado los elementos de identificación y de distinción que lo conforman. Finalmente, definir una posible tipología gastronómica a partir de los fines, valores, emociones y costumbres asociados con este patrimonio.

\section{I \\ Discursos sobre el patrimonio}

Tres planteamientos metodológicos acerca del fenómeno de patrimonio son convocados para revelar el carácter simbólico o capacidad para representar la realidad que aquél posee.

\section{Herencia y memoria colectivas}

Un primer planteamiento observa el patrimonio como herencia y memoria colectivas. 
En tanto la primera le es connatural, la memoria colectiva presupone hábitos y gestos cotidianos, recuerdos y otros valores que están dentro del "discurso familiar" que se puede extender al grupo. Esta es la posición de Henrique Urbano cuando afirma, refiriéndose al universo andino, que "herencia, memoria y patrimonio son expresiones de un mismo espacio mental y social". Se enfatiza en este caso el aspecto mental frente al social a partir de los razonamientos de Durkheim acerca de lo que es la sociedad, la cual "aúna los individuos y los transforma en grupo... los une en un ideal compartido y colectivamente vivido"?

Las cocinas regionales conforman espacios colectivos que ejemplifican esta conciencia de pertenencia a un ámbito geográfico y cultural bien delimitado, en donde el sentido de identidad con el terruño y la nostalgia por el pasado son protagonistas del discurso acerca de la tradición, y por supuesto la comida es un referente obligado en estas adiciones. Los hábitos, gestos, recuerdos, valores e ideales se conservan con mucho cuidado porque constituyen, justamente, el legado de los mayores y dan sentido al grupo. Esta memoria colectiva forma parte de la riqueza o patrimonio local. Parte de ella está compuesta por los alimentos $y$ las técnicas de cocción que confieren una personalidad, una singularidad a este grupo, que se reconoce en ellos y los distingue de otros grupos similares. Una gastronomía local o regional descansará entonces sobre el conjunto de procesos culinarios y representaciones colectivas que este espacio público genere.

En la actualidad hay un interés muy marcado en el mundo por el rescate de las cocinas regionales. Es como una vuelta a la naturaleza y a los orígenes; una necesidad por reencontrarse con ese legado que fue dejado de lado durante un buen tiempo por una falsa con ciencia de modernidad que no distingue matices o claroscuros y siempre reluce con neones bri-
Ilantes pero vacios. Se vuelve a una cocina con fundamento, con personalidad, con historia. Este proceso de reencuentro y recuperación de la memoria culinaria y gastronómica no significa, obviamente, una copia de lo que hubo sino un enriquecimiento por el aporte que los profesionales y gente de buen gusto hacen en favor de la conservación de este legado, ya que, como se señaló previamente, el grupo social responde a una configuración temporal y espacial, a una realidad de la que no puede abstraerse ${ }^{3}$.

En el nivel nacional, por ejemplo, la cocina criolla representa un conjunto de valores y pautas de comportamiento que han generado, a lo largo de los siglos, una serie de relaciones de identidad y rechazo por parte de diferentes grupos sociales. Como todo cuerpo dinámico, la cocina ha evolucionado y en el camino ha ido aceptando aportes de otras culturas como también perdiendo parte de sus propios componentes. El resultado es una cocina mestiza que tiene la cualidad de integrar una gama muy variada de colectivos sociales que se identifican de alguna manera con la cultura que esta cocina simboliza. La gastronomía peruana, que descansa fundamentalmente en esta categoría de cocina, representa la memoria del peruano que se reconoce en los alimentos, en las técnicas, en los sabores, aromas, colores y texturas de la comida criolla, en parte o totalmente. Cada grupo social, cada familia, finalmente, cada individuo encuentra en ella parte de ese legado que "sus" antepasados dejaron para el futuro.

\section{Construcción social hegemónica}

Un segundo planteo es el que define el patrimonio como una construcción social. El énfasis está puesto por el lado de la creación social o cultural a partir de algún tipo de hegemonía que intervenga, directa o indirectamente, en ella. Llorenc Prats, sobre la base de teóricos

\footnotetext{
2 Henrique Urbano, "Patrimonio y Modemidad", Turismo y Patrimonio, 1 (enero 2000): 14-16. La compilación de Pierre Nora responde a la necesidad de conservar todos aquellos objetos simbólicos e históricos que ocupan un lugar en la memoria colectiva trancesa y que pueden perderse en la sociedad moderna, Pierre Nora, comp., Les lieux de mémoire, 3 vols., Quarto/Gallimard, Paris, 1997. Lo mismo se puede decir del compendio acerca del patrimonio nacional mexicano, Enrique Florescano, coord., El patrimonio nacional de México, 2t, Consejo Nacional para la Cultura y las Artes/FCE, México, 1997.
}

3 Jesús Contreras pone el enfasis en el ámbito geográfico, siguiendo la afirma-
ción de Joseph Pla: "La cuina de un pais es el seu paisatge posat a la cassola"
para el caso catalán, y a la vez demuestra que al interior de un espacio territo-
rial es posible la diversidad y particularidades. "Tierra, cocina e identidad",
Antonio Garrido Aranda, comp., Los sabores de España y America, La Val de
Onsera, Huesca, 1999: [17]-57, También, Julia Csergo, "La constitución de la
spécialite gastronomique comme objet patrimonial en France, fin XVII'-XX" sié-
cle, L'esprit des lieux/Le patrimoine et la Cite, PUG, Grenoble, 1997 . 
como Berger y Luckman, habla de la "costrucción social de la realidad". Se plantea la necesaria intervención de un ente hegemónico social o cultural para decidir o "legitimar" lo que sería considerado patrimonio del grupo 4 . En el Perú es claro que quien ha manejado los aspectos culturales es el Estado, colonial o republicano, y siempre lo ha hecho desde una posición particular, de grupo, de casta o de clase.

Esta concepción de patrimonio gastronómico genera antagonismos presentados bajo rótulos como lo propio y lo ajeno, lo valioso y lo desechable, el buen gusto y el mal gusto. Se trata de una metodología que pone el énfasis en las discrepancias más que en las coincidencias pues introduce un elemento de conflicto como es el de hegemonía que señala lo que merece ser destacado en detrimento de lo opuesto. Siempre que esa hegemonía no sea un producto de la evolución cultural de los pueblos se le considerará un argumento que distorsiona la realidad.

Cuando el Occidente judeocristiano se instaló en América la tradición de pan y vino también lo hizo. En este caso, además de las razones gastronómicas, las religiosas tuvieron su propia dinámica. Ello significó la proscripción de cualquier elemento que jugara en paralelo con aquellos productos, bien por el lado culinario como por el religioso. ¿Qué sucedió con las hierbas y hongos alucinógenos en $\mathrm{Me}$ soamérica? ¿Cómo se percibía el consumo de la chicha en los Andes? No se trata solamente de un traslado a esta parte del planeta de la comida mediterránea sino a la homologación de un tipo de cosmovisión, para lo cual era necesario echar por tierra cualquier síntoma perturbador. Por ello resultan infantiles quienes dicen que la llegada de los europeos no significó la imposición de un tipo de comida "sino que se hace un mestizaje" gracias a los aportes locales y las formas de comer foráneas, creando potajes de indudable buen sabor y calidad. Esta versión idílica de lo que fue la Conquista y el desarrollo colonial en el Perú, que afectó en enorme

\footnotetext{
${ }^{4}$ Llorenc Prats al hablar del patrimonio como construcción social la define como 10 "que no exisle en la naturaleza, que no es algo dado, ni siquiera un fenómeno social universal, ya que no se produce en lodas las sociedades humanas ni en todos los periodos históricos" Esta suerte de artíicio, además, tiene la capacidad de ser cambiante de acuerdo con los intereses o fines del grupo. Antropología y patrimonio, Ariel, Barcelona, 1997.
}

medida la alimentación y culinaria andinas, ignora que el hecho gastronómico no puede ser analizado independientemente de las condiciones políticas, sociales y económicas 5 .

Lo mismo se puede decir de otros espacios americanos en donde la presencia europea significó un cambio drástico en las costumbres y en general en la vida de los pobladores. Carrera, refiriéndose al caso venezolano, señala que "los alimentos originados y procesados en otras culturas, e importados, no desempeñaron una función de complementariedad sino que dieron lugar a un proceso de pura y simple sustitución, modificando de manera básica y perdurable los patrones de consumo, primero en los sectores sociales de más altos ingresos, y progresivamente en casi toda la sociedad, al convertirse en paradigmas culturales y en símbolos de status social"6.

Hubo, efectivamente, maneras para enfrentar esta hegemonía. Nuevamente la cocina regional sirve de marco para hablar de esta resistencia frente a los intentos de homologación debido, justamente, a su carácter diferenciador y a la contundencia de argumentos ideológicos y representaciones colectivas al interior del espacio culinario en sus diferentes versiones: "El ámbito doméstico, rural y parroquial permitirá la conservación de una serie de costumbres gastronómicas que para los conquistadores eran formas primitivas a veces coludidas con prácticas heréticas"7.

En la actualidad hay una corriente de pensamiento que recoge esta teoría de la homologación a partir de discursos hegemónicos sobre el patrimonio gastronómico construidos con fines turísticos, entre otros. La finalidad es hacer frente al avance de la globalización y

\footnotetext{
5 Es importante recalcar que sin un esfuerzo por realizar trabajos de investigación interdisciplinaria no se avanzará en ningún sentido crítico, sino más bien seguirá existiendo una visión sesgada o reducida a gremios particulares sin formular un planteamiento coherente y cientifico acerca del proceso gastronómico en el pais. La gastronomia en particular y la alimentación en general son fenomenos sociales y culturales que requieren de la intervención de especialistas en las ciencias biológicas, humanas y sociales, nutricionistas y ecologistas, que señalen cómo es que estos tenómenos se manejan al interior de las prácticas culturales del peruano. Una lectura esclarecedora es la de Igor de Garine, - Antropologia de la Alimentación y pluridisciplinariedad". America Indigena, XLVIII-3 (julio-septiembre 1988): (635]-650.

6 Véase el Prólogo de Germán Carrera a José Rafael Lovera, Historia de la alimentación en Venezuela, $2^{\circ}$ ed, Centro de Estudios Gastronómicos, Caracas, 1998: 11-21.

7 Raúl Vargas, Prólogo a La Academia en la olla, Lima, 1995: 20-21.
} 
sus alfiles, las sociedades industrializadas, que ponen bajo un rasero a toda sociedad que tocan. Por eso la preocupación por reivindicar el "sabor auténtico" de las comidas locales, regionales o nacionales, ligado a la memoria colectiva de estos pueblos. Pienso en la "cocina novo andina" y su inquietud por presentar de una forma novedosa y creativa lo tradicional. Luego volveré sobre ella. No me parece tarea fácil llegar a esa reconstrucción en donde los protagonistas han perdido gran parte del significado original, lo mismo que las técnicas culinarias y las maneras de consumo. Tampoco se trata de retroceder en el tiempo pues el contexto es otro y las personas son otras también. De acuerdo con dicho pensamiento, soluciones como la citada igualmente manipulan el terreno gastronómico en función del interés económico, léase turísticos.

\section{Invención de la tradición}

Estas invenciones o "manipulaciones" de elementos quieren legitimarse -corno en el caso anterior-y trabajan sobre composiciones previas que han sido "descontextualizadas" o se les ha dado otro sentido, creando con ello otra realidad, otro contexto ${ }^{9}$. Se da, de acuerdo con Prats, el mecanismo de idealización de algunos elementos a la vez que se silencian otros. Inventar y construir una realidad no serían procesos antagónicos sino complementarios en diversas fases de esta creación, siempre y cuando se llegue a un grado de consenso social.

Antonio Cisneros propone una idea de la cual se puede discrepar pero es útil como una forma de invención de un discurso o tradición

\footnotetext{
8 Jesús Contreras se pregunta al igual que muchos otros "hasta qué punto son compatibles la tecnologia alimentaria y la gastronomia". "Tierra, cocina e identi-

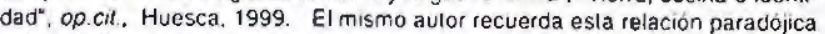
entre el alimento y la tecnologia en detrimento de la identidad en el texto pre. sentado en el III Encuentro lberoamericano. Forum.UNESCO. Universidad y Patrimonio e Interdisciplinariedad (Sonia Tello, comp Entorno al patrimonio e interdisciplinariedad. Universidad San Martin de Porres, Lima. 2002)

9 Véase Eric Hobsbawn y Terence Ranger, eds. The Invention of Tradition (Past and Present Publications), Cambridge University Press, Cambridge, 1988. Una manera de enfocar esta invencion patrimonial es la que presenta Henrique Urbano cuando indica que es posible la creacion de espacios públicos como referentes para la práclica social de un grupo o clase, a partir de los cuales sur. giran objetos, gestos, palabras, producidos justamente al interior de estos coleclivos en su dinamica social. El patrimonio "pasa a ser el recurso histórico de los grupos y clases que se apropian del espacio público y que buscan razones y la coherencia del discurso para existir en cuanto grupos o clases diferenciadas". op.cit. Lima, 2000: 17.18.
}

con los cuales se define lo que fue el mestizaje gastronómico. Señala que es posible "entender" la "facilidad" con la que los pueblos andinos aceptaron los patrones gastronómicos españoles y los asumieron. Dice que "este mestizaje se hace obviamente por intereses tanto de los conquistadores como de los conquistados. Los primeros extrañan sus formas de cocina, extrañan sus ingredientes y los traen, asimismo los conquistados poco a poco van cediendo al prestigio de lo exótico, de lo importado. Es que también van cediendo, puede parecer un poco curioso, al poder espiritual de los españoles. Ya que la conquista es eso y finalmente con las armas... España conquista por las armas pero trae muchas cosas de espiritualidad. Una religión abstracta, monoteísta y el prestigio de la palabra escrita... la comida es un tanto espiritual" ${ }^{\prime 0}$. Esta población andina debe estar agradecida, por lo tanto, porque los buenos españoles los salvaran de la idolatría y el pecado mientras les enseñaban a comer. Sería el corolario para tal propuesta, que corresponde, en efecto, a la opinión de una porción de la sociedad peruana.

Se evidencia, asimismo, la invención de una tradición europea o elitista para la sociedad limeña de la segunda mitad del XIX gracias a escritores y periodistas de pluma muy cargada que, cual críticos gastronómicos, calificaban a la comida criolla como alimento de pobres, sucios e ignorantes ${ }^{11}$. Se sentian representantes de una sociedad peruana refinada y afrancesada, de mucha cultura gastronómica, enfrentada a otro tipo de sociedad carente de cultura y nivel. ¿Será que el peruano se ha inventado una tradición gastronómica porque necesita aferrarse a esa fuerza dominadora justamente?

Actualmente los dos últimos parámetros de definición de patrimonio pueden ser

\footnotetext{
10 Antonio Cisneros, "El mestizaje gastronómico", La academia en la olla, Lima, 1995: 72 .

11 Vease a esle respeclo la obra de Manuel Alanasio Fuentes, Lima, apuntes historicos, descriptivos, esladisticos y de costumbres, Banco Industrial del Perú Lima, 1988. Isabel Álvarez llama la atención acerca del origen marginal de la cocina y música criollas por no haber sido aceptadas por la cultura oficial Señala al proposito una anécdota contada por Abraham Valdelomar en donde se denostaba la comida de una conocida cocinera bajopontina de la época, la cual era ni más ni menos que "una cena que hoy llamariamos tipicamente criolla". Mảs adelante la autora observa que hasta los años 60 en Lima habia mảs chifas que restaurantes de comida criolla. Ésta era más bien de consumo familiar o domestico. Isabel Alvarez, "La música y la gastronomia", La acade mia en la olla, Lima, 1995: 141-145; de la misma autora. Huellas y sabores del Perú, Universidad San Martin de Porres, Lima, 1997.
} 
materia de constatación, pero lo elemental es su carácter simbólico, es decir, su capacidad para representar una identidad. De manera que los tres planteamientos serán útiles para formular más adelante el concepto de patrimonio gastronómico ideal, construido a partir de elementos disímiles pero precisos, para crear algún tipo de identidad dentro de la población, sea porque siente que comparte la misma memoria colectiva, porque hay un ente superior que así lo establece, o porque la invención y manipulación han sido efectivas.

\section{II}

\section{La gastronomía como patrimonio de la Nación}

\section{Criterios para su definición}

El discurso acerca del patrimonio gastronómico ha pasado de ser soporte de la memoria para convertirse en soporte de la identidad. Esta idea proviene de André Desvalées cuando se refiere al patrimonio museístico y lo que es digno de conservarse y transmitirse como valor patrimonial de la

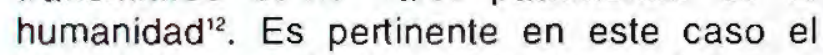
conocimiento de la diversidad gastronómica en el Perú para poder encontrar en ella esos referentes de identidad imprescindibles para la construcción del patrimonio, llámense costumbres, fines, valores o emociones. A la vez, esta identidad, construida sobre sólidas bases de conocimiento y aceptación, es una vacuna contra cualquier intento por distorsionar el patrimonio gastronómico a partir de conductas que globalizan y homogenizan. Esta apuesta por el conocimiento de lo propio, lo singular, lo permanente dentro de los patrones culturales locales, regionales o nacional, es un avance para la definición del verdadero patrimonio gastronómico de la sociedad, digno de conservarse y transmitirse.

La comida es una de las expresiones más específicas de un pueblo o de una nación. Este sustento, restringido tradicionalmente a la familia y a la comunidad, encontró en espacios públicos como el restaurante un lugar idóneo

12 André Desvallées, "Un tournant de ta muséologie", Brises, 10 (1987): 5-12. para desarrollarse con libertad y posibilidades de indagación, experimentación y proyección. A todo ello se asocia la gastronomía y forma parte del patrimonio cultural'3.

Pero, ¿quién está en capacidad para formalizar, manejar, explicar, difundir, conservar, restaurar, en fin, gestionar este patrimonio? El Estado es el responsable formal de esta labor; es más sin el apoyo político es muy difícil poder diseñar cualquier proyecto sobre patrimonio, en este caso, gastronómico. Las asociaciones gastronómicas están obligadas a cautelar la calidad de los productos, platillos y sistemas culinarios que se firmen como locales. La Academia en tanto espacio de diálogo, discusión y exploración científica, vale decir universidades, museos y centros de documentación, con un trabajo sistemático en archivos, bibliotecas, centros de información, laboratorios y cocinas. Es un problema de todos, ciertamente, sin embargo el último es el lugar natural para el desarrollo de la investigación en patrimonio para que los otros puedan avanzar en este camino con un conocimiento riguroso acerca del tema gastronómico ${ }^{14}$. El mer-

\footnotetext{
13 Pascal Ory señala la comida como aquello que todo ser humano identifica como vida y que al final es lo que queda en ta memoria colectiva; lo que logra la integración o asimilación dentro del grupo o comunidad. Asimismo llama la atención sobre que nunca como hoy se ha escrito tanto acerca del tema gastronómico. "La gastronomie", Pierre Nora, comp., Les lieux de mémoire, 3, Quarto/Gallimard, Paris, 1997: 3743-3768. Dentro de esta misma linea, Igor de Garine apunta que si en los animales la alimentación corresponde a la necesidad de satisfacer una necesidad primaria como es la nutrición, para lo cual se guian por el instinto, en el hombre, dotado de cultura, este fenómeno es compartido por los miembros del grupo, en donde los comportamientos alimentarios son, en gran medida, parte del aprendizaje desde la infancia, influido a la vez por los aspectos materiales y no materiales do esa cultura. Igor de Garine, Introduction, Cuisines, reflets des sociétés, Éditions Sépia-Musée del'Homme, 1996: [9]-28; del mismo autor. "Le sucre et le sel", Joum d'Agric, XXXV (1988): (5)-14.

14 La universidad peruana ha demorado en comprender la necesidad de profundizar en los estudios sobre patrimonio cullural, y gastronómico en particular. Es una diferencia abismal la que separa la investigación efectuada en sociedades de muy similar desarrollo a la peruana, como México, Colombia, Venezuela, Argentina o Chile, de la que se hace localmente. El resultado es realmente deprimente si comparamos la producción peruana con la europea. Sin embargo el reto está en acortar esta diferencia a partir de estudios serios y rigurosos sobre el tema gastronómico. Para mostrar solamente tres ejemplos de cómo se trabaja en lo que respecta a la investigación y puesta en valor del patrimonio gastronómico en otros paises remito al lector al ensayo de Jorge Alberto Garufi Aglamisis, "Valoración económica y cultural del patrimonio alimentario regional", Antonio Garrido Aranda, comp., op.cit., Córdoba, 2001: 27 55, para la Argentina. En España se ha creado un Colectivo para el desarrollo rural de Tierra de Campos definido como "Patrimonio Gastronómico", que busca fomentar junto con la riqueza gastronómica, los atractivos artistico-culturales y naturales de Castilla y León, um\% cdrtcampos.es/colectivo/patrimonio.htm. E caso más conocido, seguramente es el Consejo Nacional para las Artes Culinarias (CNAC), creado en Francia en diciembre de 1989, que agrupa a los grandes chefs, distinguidas personalidades y empresarios agroalimentarios, con el encargo de los Ministerios de Agricultura, Cultura, Educación, Salud y Turismo, de coordinar una "politica del sabor" -con sesiones de degustación en colegios y universidades para educar el gusto- $y$ de establecer un inventario del patrimonio culinario "en el marco de una política global de revalorización de los productos regionales" sobre la base de los lugares seleccionados como los más productos regionales sobre la base de los lugares seleccionados como los mas comer: una historia de buen gusto, wmw.france.diplomatie.frnabel_france.
} 
cado turístico es un factor complementario en la gestión del patrimonio gastronómico ${ }^{15}$.

Cuando hay un manejo del patrimonio gastronómico desde una "mirada turística" surgen creaciones como la "cocina novo andina", que se presenta como "expresión clara de la necesidad de rescatar lo mejor del rico acervo culinario peruano sin descuidar de ninguna forma la creatividad y enseñar al mundo a disfrutar de los productos y recetas que legaron sus antepasados"16. Qué bueno y qué oportuno; sin embargo, cuando la indagación va un poco más allá de lo publicitado brota la pregunta ¿qué tanto de investigación hubo antes de lanzarse con la idea?

"La comida de un pueblo forma parte fundamental de su patrimonio cultural... es producto de la interacción de la humanidad con los recursos de la naturaleza y la tecnología, los gustos, la experiencia, los sentimientos, la economía y multitud de elementos" ${ }^{117}$. Así de fácil se puede resumir lo que significa el patrimonio gastronómico de un pueblo. En el Perú esa interacción es muy afecta a la aceptación de innumerables influencias extranjeras; parece formar parte de su propia idiosincrasia. De alli lo fascinante que resulta seguir las diferentes pistas que conduzcan a los orígenes de diferentes platillos, tanto en lo que concierne a los ingredientes como a las técnicas culinarias. Se busca en todo caso establecer las coincidencias y encuentros con cocinas europeas y asiáticas que comparten con la peruana, fundamentalmente con la criolla, un conjunto de productos y nociones gastronómicas. La diferencia entre ellas está, obviamente, en la historia, valores y representaciones asociados con cada cocina.

\footnotetext{
15 Es oportuno señalar algunas pesquisas sobre turismo gastronómico que merecen ser consultadas, en este caso experiencias mexicanas: Alicia Bernard y Patricia Dominguez, "Rutas de arte y gastronomía. Una propuesta inexplora. da", Estudios y Perspectivas en Turismo, 10 (enero-abril 2001): 76-90; de las mismas autoras, "Cocinas regionales. Herencia en peligro", Estudios y Perspectivas en Turismo, 11 (julio-octubre 2002): 335-346. También Regina Schlüter, "Turismo y patrimonio cultural. La gastronomia en la región pampeana", Regina G. Schlüter y Juana A. Norrild, coords., Turismo y patrimonio en el siglo $X X$ I, Centro de Investigaciones y Estudios Turisticos, Buenos.Aires. 2002: 153-160. Asimismo Gabriela Benavides de Rivero, "La ruta del cebiche" Alimentación y Gastronomia. II Coloquio Internacional de Gastronomia, Patrimonio y Turismo, Gabriela Benavides de Rivero, comp. Universidad San Martin de Porres, Lima, 2003.

16 Alain Spaey, "La gastronomia y el turismo hoy", La academia en la olla, Lima, 1995: 37.

17 Luis Alberto Vargas, "Un banquete de la cocina mexicana", Enrique Florescano, coord. op.cit., México, 1997: 266-288. Véase, asimismo, Sonia Corcuera de Mancera, Entre gula y templanza. Un aspecto de la historia mexicana, $3^{\circ}$ ed, Fondo de Cultura Económica, México, 1996.
}

\section{Poniendo en orden los términos}

\section{ALIMENTACIÓN}

Es muy fácil caer en el error acerca del concepto de alimentación como sinónimo de nutrición, vale decir, la búsqueda por satisfacer una necesidad vital que compense el gasto de energías a través de una dieta completa en proteínas, hidratos, vitaminas y minerales ${ }^{18}$. Esta lucha por la supervivencia de la especie está en la base de la alimentación, efectivamente; sin embargo no se puede desligar de ella el significado cultural, aquello que permite que los integrantes de un grupo se identifiquen entre ellos y a la vez se diferencien de otros. Es uno de los factores más importantes para el binomio identidad-distinción que aparece en la sociedad.

La investigación acerca de la alimentación y sus alcances en la cultura está en uno de sus mejores momentos. Se ha sistematizado mucha información y hay planteamientos realmente luminosos sobre lo que este fenómeno representa' ${ }^{19}$. Uno de esos esquemas es el que Jiménez ofrece como pauta para un análisis científico. Él señala cuatro niveles de interpretación: En primer lugar el de la supervivencia como imperativo biológico, común a todos los grupos humanos. Obligado a comer, el hombre en su calidad de animal omnívoro ha logrado sobrevivir en diversos ecosistemas. Un segundo nivel observa las técnicas para con

\footnotetext{
18 Santiago Antúnez de Mayolo ha dedicado parte importante de sus esfuerzos científicos a la difusión de la dimensión nutricia de la dieta precolombina. En el III Congreso Peruano "El Hombre y la Cultura Andina" (1977) sustentó la necesidad de reconocer la importancia de la cultura andina en el aspecto alimenticio. Formuló una taxonomia a partir de los ecosistemas, productos, sistemas de conservación y potajes, que con algunas variantes ha servido para posteriores clasificaciones. El hombre andino contó con las proteinas animales, vegetales, minerales, vitaminas, cereales, menestras, oleaginosas, lipidos. tubérculos, chicha y coca necesarios para un sustento optimo de acuerdo con ella. Lamentablemente esta racionalidad entre paisaje y consumo se quebró con la llegada de los españoles. A propósito de lo cual Antúnez de Mayolo insiste en la comparación entre la nutrición pretérita y la desnutrición contemporánea en el Perú. Santiago Antúnez de Mayolo, "La nutrición en el antiguo Perú", Actas y Trabajos del III Congreso Peruano El hombre y la cultura andina, Segunda Serie, T. V. Lima, 1980; edición ampliada por el Banco Central de Reserva del Perú, Lima, 1981. En la misma linea están las obras de Ciro Hurlado, véase La alimentación en el Tawantinsuyu, Instituto de Cultura Alimentaria Andina/San Marcos, Lima, 2000.

19 Este tema empezó a ser estudiado con una metodologia apropiada a partir de la Escuela de los Annales, desde el contexto material en que se han desarollado las civilizaciones y cómo al interior se produce esle aspecto en particular. Dentro de esta linea se comprenden las obras ya citadas de Ory y JeanLouis Flandrin, "La distinción a Través del gusto" Historia de la vida privada, 1.5. Taurus, Madrid, 1990. Lovera y las compilaciones de Garrido Aranda Asimismo Cuisines, Reflets des Sociétés, Editions Sépia-Musée de l'Homme, Paris, 1996; Alimentación y gastronomia: cinco siglos de intercambios entre Europa y América, Asociación Española de Americanistas/Newbook Ediciones, Pamplona, 1998; Janet Long, coord., Conquista y Comida. Consecuencias del encuentro de dos mundos, UNAM, México, 1997.
} 
seguir alimento. Es una "capacidad que los animales comparten hasta cierto grado con el hombre, pero que entre los humanos adquiere formas inteligentes, no instintivas, que son ya parte de la cultura". Este proceso de localización de recursos, aplicación de técnicas para conseguirlos, transportarlos y conservarlos se inscribe dentro de un rango económico. Un tercer nivel busca ingresar en el universo sociocultural de la alimentación, construido sobre la base de reglas, códigos e instituciones. El alimento se integra en este sistema para cumplir una función de relación social y de apoyo a muy diversos objetivos. El último nivel -que es estrictamente humano- delimita el ámbito de las creencias y del sistema de valores. "Un complejo de formas de comportamiento y de significados simbólicos que se relacionan con todos los aspectos de la organización social y de la cultura"20.

El hecho alimentario va mucho más allá de la nutrición. Tiene que ver con el poder político que lo gestiona, desde la producción hasta la distribución, de acuerdo con la coyuntura. Por otro lado cada cultura desarrolia un tejido de relaciones sociales alrededor de los alimentos, en donde las fuerzas o deidades tienen que ver en grados diversos: en algunos casos se llega a la deificación de determinado alimento porque se le relaciona directamente con la idea de vida o supervivencia. Es como cerrar el círculo.

En el mundo prehispánico hubo una relación con el alimento que se define como "seguridad alimentaria"21. Ésta se manifestaba a través de una política estatal que disponía la construcción de almacenes para alimentos con diversidad de productos, previniendo posteriores catástrofes, sequías e inundaciones, bási-

\footnotetext{
20 Alfredo Jiménez, op.cit., Pamplona, 1998. José Rałael Lovera da muchas luces sobre el tratamiento melodológico de la producción historiográfica sobre la alimentación, y señala hasta cuatro enfoques para este manejo: la aproximación psico-sociológica (alimentos y cultura), la económica (producción-consumo); la nutricional (dieta) y alimentación como patrimonio. Finalmente propone una metodologia para estudiar los regimenes alimenticios en Venezuela. Historia de la Alimentación en Venezuela, Centro de Estudios gastrond́micos. Caracas, 1998

21 Luis Alberto Vargas, "La seguridad alimentaria en Móxico", Antonio Garrido Aranda, comp., op.cit., Córdoba, 2001: 87-95. En el Perú la preocupación por este aspecto ha sido recogida en las obras citadas de Antúnez de Mayolo. También en Roger Ravines, comp. Tecnologia andina, Instituto de Estudios Peruanos, 1978, en los capitulos dedicados a los temas de Agricultura y riego. y Almacenamiento y alimentación. Asimismo se preocupa por el tema Hans Horkheimer, Alimentación y obtención de alimentos en el Penú prehispánico. Universidad Nacional Mayor de San Marcos, Lima, 1973. Para la region selvâtica, Alberto Chirit, cemp., Elnicidad y ecolog/a, Centro de Investigación y Promoción Amazónica, Lima, 1978.
}

camente. Es un problema que remite inmediatamente a las técnicas de conservación, sea por deshidratación (por calor y frío) o por el uso de salitre, cal, ají, ichu, arcilla, arena u otros medios preservantes; cada familia tenía variados sistemas de almacenamiento de acuerdo con lo que la naturaleza ofrecía y que era considerado alimento por la sociedad, aunque no fuese de uso cotidiano. Se preparaban y consumían muchas de las cosas que normalmente desechaban. Objetivo fundamental era enfrentar el posible hambre o penuria. En las sociedades antiguas -como las prehispánica- se ofrecía comida a los muertos y potencias para obtener el alimento; éste se convirtió en un medio de comunicación entre vivos y muertos ${ }^{22}$.

\section{CULINARIA}

La alimentación cumple con una función biológica al suministrar al cuerpo las sustancias indispensables para su subsistencia, al tiempo que traduce un conjunto de relaciones sociales y económicas surgidas a partir de este consumo, además del valor cultural inherente. Sin embargo, los diversos colectivos preparan sus platillos de manera diferente. Parten de variados principios de elaboración, transformación, cocción y conservación de alimentos que buscan satisfacer la subsistencia pero también las necesidades culturales antes mencionadas. Se habla entonces de tecnología culinaria y hasta de sistemas culinarios intentando una tipología de los preparados de acuerdo con los diversos grupos socioculturales.

La culinaria (término que proviene de coquere: cocer, y coquinare: guisar, sazonar los alimentos) es el conjunto de técnicas reglamentadas y complementadas por leyes de la ciencia para el preparado de los alimentos. Estos procesos descansan sobre bases científicas como la física, la química, la bromatología, la fisiología y la dietética. Se puede decir que esta selección y preparación del alimento corresponde a la parte operativa de la cocina.

\footnotetext{
22 Igor de Garine desarrolla el tema del hambre y establece una tipologia para los pueblos Masa y Muzey en relación con este aspecto de seguridad alimenta. ria. Es un esquema de investigación que utiliza términos como penuria, morir de hambre, escasez, etc. Una investigación en este sentido es una asignatura pendiente en el Perú, desde tiempos prehispánicos hasta los contemporáneos, que contemple alimentación, conservación, prácticas higiénicas y costumbres de mesa. Véase Igor de Garine, "Temas alimentarios en la expresión verbal de los Masa y Muzey del nerte de Camerún y Chad", Antonio Garrido Aranda, comp., op.cit., Córdoba, 2001: 57-83.
} 
La tecnología culinaria como cualquier otro tipo de técnica es trascendental para el desarrollo de la sociedad y debe ser analizada dentro del contexto cultural en que se origina. La técnica es una respuesta práctica frente a una necesidad concreta. En este caso se trata del conjunto de procedimientos para que los productos de la naturaleza se transformen en alimento útil para satisfacer al homo sapiens en su necesidad de supervivencia. Así como el hombre ha evolucionado, las técnicas, y entre ellas las que competen a la cocina, también. Pasó de recolectar su alimento a producirlo: este avance tecnológico del Neolítico es culminante dentro de la historia de la humanidad. De todos los recursos naturales que las sociedades pudieron aprovechar en esta labor por subsistir y desarrollarse, los cereales y las legumbres fueron los pilares sobre los que descansó gran parte de esta evolución. De fácil cultivo y conservación ambos marcaban la dieta cotidiana, complementada con algún tipo de carne. Hoy en día el alimento animal es más importante y los cereales, legumbres, tubérculos, verduras y hierbas son compañia más que protagonistas. La tecnología ha tenido mucho que ver con ello por los avances en la conservación y cocción de los alimentos de origen animal.

Un tema de larga data pero a la vez de actualidad es el de "industria alimentaria", que permite la conservación y cocción de los productos manteniendo sus calidades nutritivas y solucionando al mismo tiempo el problema del transporte de los mismos hacia destinos alejados. Espacio y tiempo son categorías fundamentales en este avance, sin perder de vista lo que la culinaria tiene por naturaleza: el arte de transformar los productos en alimentos convenientes y útiles para el cuerpo humano. Esta tecnología de la alimentación ha acompañado al hombre desde que descubrió el fuego y aprendió a conservar sus alimentos; sin embargo la relación con la comida se fue haciendo cada vez más mediática y en el siglo $X X$ apareció un fenómeno llamado "cocina industrial". Considerada como un buen negocio para productores, transportistas y vendedores interesados, genera desconfianza entre quienes dudan de los valores nutritivos y gastronómicos contenidos en ella. Los consumidores rechazan el carácter artificial de este tipo de alimento debido a los procesos físicos y químicos propios de su manejo ${ }^{23}$. Volveré luego sobre este tema en relación con la falta de identidad de la sociedad con dicho producto.

La posición de quienes ofrecen estos productos está en la acera de enfrente. Es el caso del chef Georges Pralus, inventor de la cocina al vacío. Señala que con ello ha abierto nuevos campos en la investigación gastronómica, y afirma que los productos manejados bajo esta técnica consiguen una calidad superior a la obtenida mediante la cocción tradicional, pues los hace más digestivos y elimina el fenómeno de la fermentación: "Al vacío, a baja temperatura, los platos pueden reproducir los sabores de aquella cocina a fuego lento que realizaban nuestras abuelas, pero con material moderno y sin que el aire provoque oxidación alguna". Lo más importante, según el afamado cocinero, es que se respeta el sabor de los alimentos, se conservan las vitaminas, los oligoelementos y las sales minerales, y que las grasas no se transforman ${ }^{24}$.

\section{GASTRONOMÍA}

La gastronomía es el arte de comer bien y tiene que ver con alimentarse de acuerdo con una precisa técnica culinaria. Pero además de ello significa saborear y gozar con un alimento, sentir el placer de sentarse a la mesa para comer, y si es en buena compañía mejor: "Sentarse a la mesa ofrece... la oportunidad de disertar sobre los manjares elegidos" ejerciendo el sentido crítico. En ello Francia se impuso desde hace mucho tiempo gracias a los inventores del género de crítica gastronómica, Alexandre Grimod de la Reyniére y Anthelme BrillatSavarin, aunque el primero nunca habló de gastronomía ni de gastrónomos sino de golosos y de anfitriones, personas ilustradas y entendidas en artes, deportes y de gusto irreprochable. Un verdadero gourmand, en cualquier caso, hacia gala de su fino paladar al "no comer nunca más de lo que pueda digerir con cordura y no beber más de lo que pueda soportar con plena conciencia"25.

\footnotetext{
23 Jesús Contreras, op.cit, Lima. 2002.

24 Florence Raynal, "Entrevista a Georges Pralus", Label France, 26, (diciem. bre 1996).

25 Alexander Grimod de la Reyniere, Manual de anfitriones y guia de golasas. Tusquets, Barcelona, 1980.
} 
La palabra "gastronomia" fue tomada del poema que en 1801 escribió Berchoux, La Gastronomie. Según Brillat-Savarin la gastronomia se ocupa, además del gusto y la clasificación de los alimentos por su sabor, de la acción de los alimentos sobre la moral, la imaginación y las percepciones humanas, y señala lo que merece ser divulgado en otras latitudes: "hace que un festín sabiamente ordenado sea como un resumen del mundo, en el que cada parte figura como su representación"26.

Una feliz comparación hace Isabel Álvarez de la cocina con la música. Señala que si la música significa armonía de los tonos, la cocina significa armonía de los gustos. "La creación y la emoción preceden tanto a la música como a la cocina. Puede tratarse de un plato nuevo o de una nueva sinfonía... tanto música como comida sirven para comunicarnos, acercarnos, para recrear y para sentir bien un momento" ${ }^{\prime 2}$. Este concepto de armonía es fundamental en gastronomía pues recorre el espacio de la cocina desde que el producto se combina con otro para nutrir al hombre, pasa por utilizar la técnica culinaria conveniente, hasta llegar a la mesa para servirse y consumirse adecuadamente. Viene al punto una de las máximas del duque de La Rochefoucauld: "el comer es una necesidad, pero el comer inteligentemente es una arte".

Un tema polémico es el de la posibilidad de señalar una gastronomía entre culturas que no han dejado testimonio escrito -o tradición oral sin mácula de influencia exterior-sobre el manejo del gusto o el placer por determinados alimentos. Específicamente me pregunto si se puede hablar de gastronomía en la sociedad andina prehispánica, en donde hubo una preocupación constante por la nutrición y la conservación de los alimentos a partir de lo que ya se señaló como "seguridad alimentaria" pero no se puede afirmar nada acerca del paladar y el olfato. Sería conveniente un análisis exhaustivo en los vocabularios y gramáticas de lengua quechua sobre las palabras asociadas con ello.
Igor de Garine ha estudiado los términos que utilizan los Masa y Muzey para designar sus alimentos y ha encontrado algunos que, efectivamente, califican las comidas como sabrosas, las que, además, tienen el sentido de "bello" y "bueno". No olvidemos que el ejercicio gustativo tiene una dimensión moral y hedonista. Existe entre ellos la percepción sobre los alimentos en tanto adecuados para su consumo, pero también un determinado gusto. Hay términos que significan "comer bien" y están asociados con otros que señalan lo dulce, agrio o picante. Es más, hay conciencia de glotonería y de felicidad o prosperidad asociadas con la comida, específicamente con lo grasoso o sustanciosos ${ }^{28}$.

\section{En torno de los sabores y los aromas. El gusto.}

El gusto es la memoria del paladar y del olfato, y está en el centro del fenómeno gastronómico. Esto es punto crucial en lo que a gastronomía toca: el gusto y el placer de la mesa. De los aforismos de Brillat-Savarin, el nono señala que "el descubrimiento de un nuevo plato hace más en beneficio del género humano que el descubrimiento de una estrella"29.

Como ya se dijo la palabra "gastronomía" comienza a manejarse en París a principios del siglo XIX, y en relación con la literatura crítica en este campo, debido a la aparición de restaurantes en donde se hacía gala de los mejores manjares. Este juicio sensorial pretendía establecer una estética del gusto y de las buenas maneras en la mesa. La instauración del restaurante en la vida cotidiana significó para el cocinero, acostumbrado a servir a nobles y aristócratas, un nuevo tipo de relación con sus comensales: burgueses, profesionales y gente de Estado, con hábitos alimenticios diferentes. Esta interacción dio pie a nuevas creaciones y también a combinaciones interesantes con las comidas regionales, puesto que
26 Anthelme Brillal-Savarın, Fisiologia del guslo, Aguilar, Madrid, 1987.

27 Isabel Alvarez, op cit., Lima 1995; de la misma aulora, Para ver, oir y degustar. Lima. sus cantares, sus dichos y sus calles con aji. Universidad San Martin de Porres. Lima, 1997
28 Igor de Garine, op.cit., Córdoba, 2001. Asi como en el caso de la concepción de hambre, la de gusto o placer por el alimento, vale decir el concepto de gastronomia no ha sido rastreado en los vocabularios de lengua indigena o recopilaciones de tradición oral. Por ejemplo en el repertorio de términos alimenticios de Toribio Mejía Xespe no aparece nada que lo señale, "Kausay. Alimentos de los indios", Wirakocha, 1-1 (enero 1931): [9]-24.

29 A. Brillat-Savarin, op.cit., Madrid, 1987; p. 8. 
muchos de los clientes eran diputados de las provincias o representantes de los comités revolucionarios que se aferraban a sus guisos y potajes oriundos. Habia que satisfacerlos con sabor, aroma e imaginación. Tras este primer periodo de adaptación de los espacios públicos, se publicó la primera obra que trataba de orientar a los profesionales de la restauración. Fue el Livre de cuisine, de Jules Gouffé, que además va dando cuerpo a un sentido de cocina francesa y se inscribe dentro de la formación de la conciencia nacional y el orgullo por la patria que recorrió esta Europa decimonónica ${ }^{30}$.

Sin embargo gastronomía también designa un aspecto de la cultura culinaria que consiste en saber comer, ejercitar los sentidos gustativo, olfativo y visual frente a un platillo, disfrutar de lo que se consume, tanto por el alimento como por el ambiente agradable que enmarca la experiencia. Entendida desde este punto de vista la gastronomía constituye el último peldaño en la escala del conocimiento y arte de comer.

Sabemos que Francia es la patria de las artes culinarias y el buen gusto por la comida y la bebida debido al desarrollo de su gastronomia. Lo que corresponde es preguntarse el porqué de tal merecimiento: ¿será por sus productos de mar y huerta, o por el perfeccionamiento de diversas técnicas, o por hechos extra culinarios como un traslado de la imagen refinada de la sociedad francesa hacia su cocina? De todo hay un poco, indudablemente; sin embrago el elemento definitorio para este fenómeno es el feliz encuentro de tres tradiciones culinarias que sumaron y no restaron en el devenir de la historia gastronómica del pueblo francés. Los galos sabían comer y esto quedó registrado en las crónicas de viajeros latinos como Varrón que subrayaba "lo excelente de la comida francesa". Era una cocina rústica, con fundamento y exquisita. La llegada de los romanos enriqueció y refinó la mesa gala y

\footnotetext{
30 En la "introducción" Néstor Luján señala su pretension de que esta historia "sea una crónica de los aspectos más variados, más seductores y reconfortantes en el arte de comer como son la fantasia, la invención, el trabajo y. si se quiere, la dedicación constante del hombre para que la necesaria alimentación se convierta en algo tentador, utilizable y exquisito $0^{\circ}$. Historia de la gastronomia, Folı. Barcelona, 1997. Tambièn resulla muy útil a esle propósito Manuel Martinez Llopis, Historia de la gastronomia española. Alianza, Madrid, 1989.
}

reafirmó su carácter regional, además de resaltar el carácter hedonista de la comida, sobre todo en ocasiones festivas como las bodas campesinas y en las meriendas campestres por supuesto. A partir del siglo $\mathrm{V}$ los invasores francos, de acuerdo con Jean-Robert Pitte, especialista en historia de la gastronomía francesa, "acentuaron la noción de libertad en las preparaciones culinarias y reforzaron el placer de disfrutar bebiendo". Luego las órdenes monásticas efectuaron avances técnicos importantes para mejorar la calidad de los vinos.

Se trata de una cocina que comparte con el resto de Europa una serie de características como el consumo de pan duro, preferencia por el queso, el tocino, y la combinación de dulce con salado y agrio con dulce. La llegada de productos americanos a la mesa francesa causó cambios importantes por la variedad de platillos que se elaboraron a partir de ellos, pero siempre manteniendo el mismo placer por compartir los alimentos con los invitados, llegando inclusive a la gula. La Iglesia sabía perdonar. El momento culminante de la comida como portadora de placer y elemento de distinción social y cultural llegó con Luis XIV, cuando se instaló la etiqueta junto al sentido de lo que se debía comer, todo ello en medio de un ceremonial que desarrollaba al milímetro lo que se llamó "servicio a la francesa". Significaba que todos los platos debían servirse al mismo tiempo y los comensales acercarse a la mesa siguiendo indicaciones precisas que buscaban crear un ambiente agradable y propicio para la conversación, la misma que indefectiblemente giraba en torno de las delicias culinarias que degustaban. Surge así el arte de la mesa que tiene mucho que ver con el arte de la política. Juntas serán imbatibles en las gestiones diplomáticas.

A fines del XVIII, y en medio de los afanes revolucionarios, la gastronomía tuvo su propia "toma de la Bastilla" cuando el cocinero francés Beauvilliers inauguró en París el primer restaurante. El ejemplo no tardó en ser seguido por cocineros sin empleo y entonces "la gran cocina salió a la calle". Época para la crítica gastronómica como vimos. Hasta los años setenta del siglo XX la cocina francesa se caracterizó por su variedad, ampulosidad y el uso de la mantequilla en todos los preparados. A partir de entonces una nueva corriente, la "nou- 
velle cuisine", más ligera en todo sentido, causó toda una moda gastronómica que declinó -como toda moda- a fines de los ochenta con el retorno a lo francés auténtico, regional, "rico rico" para usar la frase de Karlos Arguiñano, pero sin perder lo positivo que aquella moda preocupada por la dietética inculcó en los cocineros ${ }^{31}$.

Así como se construye el buen gusto también se puede destruir. Prueba de ello es la aceptación de la fast food. Es un fenómeno mundial que recorre todas las capas sociales, esperemos que no todas las culturales. De ser asi el fin del buen gusto está ad portas.

La "comida rápida" no tiene nada que ver con gastronomía, es un producto comercial que responde a objetivos que están muy lejos de los nutritivos o culturales. Diego Rangel la presenta en estos términos: "una de las formas más rápidas y quizás más prácticas de hacer dinero fue a través de las franquicias del estómago"32. El sabor está presente, como no. Para un paladar no educado será lo mismo una hamburguesa al paso que un tradicional estofado de ternera. El problema es que esta educación toma tiempo y requiere cuidado. Qué se puede hacer frente a una opinión como la siguiente, ofrecida al interior de un evento académico: "¿Qué diferencia hay entre comida rápida, un vendedor ambulante, un lugar para comer chicharrones y tamales o donde se puede comer rápidamente anticuchos con emoliente y chicha?"33. El Perú, rico en gastronomía, una de las mejores del mundo, no puede permitirse caer hasta esos niveles. Es necesario rescatar el aspecto creativo y estético de la comida, valorar mucho más los productos y técnicas participantes, así como la diferencia frente a otras comidas.

Si hay que combatir este mal gusto, ¿por qué no utilizar las mismas armas?. Así lo

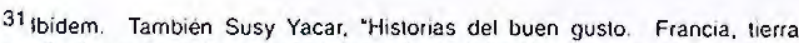
predilecta de la gastronomia", A fuego iento, II-30 (16 de enero, 2000); Julia Csergn, op.cit., Grenoble, 1997. Un aspecto interesante en esta etapa de fas. tuosidad y brillo, y sobre todo de marcadas diferencias sociales, visibles en torno de la gourmandise, las formas de consumo, la estética de la alimentación. y el surgimiento de una "moral alimentaria" se reflejan de manera no tan armoniosa en escritores, poetas, recetarios y pensamientos. En palabras de JeasJacques Brochier, que escribe el Prefacio a esta obra, este fin de siglo es la glo. rificación del horror en literatura: Marie-Claire Bancquart, Fin de sieclo gourmande 1880-1900. Presses Universitaires de France. Paris, 2001.

32 Diego Rangel, Comentario a Carlos Zuñniga, "El fenómeno de la comida rá. pida", La academia en la olla, Lima, 1995: 103-104.

33 Miguel Grau Malachowski. Comentarıo a Carlos Zúñiga, op cit., Lima, 1995: 104-106.
}

han entendido "aquellos productores que -amparándose en la 'especificidad', la 'tradición', la 'calidad' o lo 'conocido', lo 'artesanal', lo 'casero', el 'sabor' o lo 'propio' - pretenden concurrir en un mercado cada vez más monopolizado por las grandes marcas industriales y los grandes distribuidores... Es precisamente la progresiva homogenización y la globalización alimentarias lo que provoca una cierta 'nostalgia' relativa a los modos de comer y a los platos que han ido desapareciendo, suscitando un interés por regresar a las fuentes de los 'patrimonios culinarios'. La 'insipidez' de tantos alimentos ofrecidos por la industria agroalimentaria provocaría el recuerdo más o menos mitificado de las 'delicias' y 'variedades' de ayer ${ }^{\prime \prime 4}$.

\section{Cultura gastronómica: Identidad versus distinción}

La comida es uno de los elementos de cohesión y de identidad de los pueblos. Es a través de los sabores, olores, colores y texturas como el hombre aprende a identificar los alimentos, que se convierten en referentes de situaciones particulares de la vida personal, familiar y social. Se asocia con recuerdos, tradiciones y vivencias. "De esta suerte las personas y los grupos deciden lo que es y lo que no es comestible, lo adecuado para las cambiantes circunstancias, lo que les gusta y lo que recha$z^{\prime \prime}{ }^{135}$. Esta identificación se da en tanto son elementos compartidos por el grupo social al que se pertenece o por la cultura que evidencia. El sujeto se reconoce en el grupo y viceversa.

Para que una representación identitaria sea efectiva y anime a la adherencia y no al alejamiento, aquella no puede estar muy lejos del pensamiento social. Bourdieu plantea el concepto de "habitus" como una interiorización del mundo social a manera de esquema inconsciente de percepción mediante el cual el hombre organiza su visión del mundo, convirtiéndolo en un "cuerpo habituado" ${ }^{136}$. Este esquema

\footnotetext{
34 Jesús Contreras, op. cit., Córdoba, 1999 y Lima, 2002.

35 Luis Alberto Vargas, op.cit., Mexico, 1997. Tambièn Igor de Garine, "Views about food prejudice and stereotypes", Social Science information, 40-3 Sage Publications, London, 2001: [487]-507.

36 Pierre Bourdieu, op.cit., Madrid, 1988. Este aspecto es abordado de manera sencilla por Silvia Guzmán, "Abrir la boca para restaurar la utopia", Clarin (26 de enero, 2002): 2 .
} 
preside los comportamientos y representaciones generando una distinción de acuerdo con los niveles sociales.

¿Con qué cocina se identifica el peruano? ¿Cuál lo distingue? ¿Es posible hablar de una gastronomía peruana?. La cultura culinaria de un ciudadano y un campesino, así como la de un criollo y la de un andino, no pueden ser iguales. Provienen de realidades y tradiciones diterentes, por tanto sus costumbres, emociones, valores y fines tienen referentes particulares en cuanto a los lugares de producción, a los alimentos, a las técnicas culinarias y a las maneras de consumo. El error está en homologar cocina criolla y cocina peruana. ¿Qué pasa entonces con la cocina de las comunidades andinas, altoandinas o amazónicas? Tampoco es lo mismo comer en las capitales de provincias que en los poblados circundantes. Cada una de estas cocinas tiene sus elementos de identificación. En cualquier caso no existe una gastronomia compartida por todo el Perú.

Por otro lado también es cierto que el tipo de cocina actúa como factor de diferenciación cultural y crea diferencias de orden social. Establece una distinción entre "lo elegante y vulgar, lo bueno y malo, y lo comestible y no comestible". Se crea una división entre la comida de 'elites' y la del pueblo, desde los niveles de acceso al alimento a partir de las posibilidades socioeconómicas hasta la difusión de los conocimientos culinarios. Ortiz García señala que "al comer se incorporan no sólo las características físicas de los alimentos, sino también sus valores simbólicos e imaginarios que, de la misma forma que las cualidades nutritivas, pasan a formar parte del propio ser. Así pues, la comida no sólo es buena para comer y para pensar (en la adjetivación de materialistas y estructuralistas), sino, antes incluso, muy buena para ser y distinguirse ${ }^{137}$.

El término mestizaje ha venido a solucionar en parte la convivencia de una variedad de sistemas culinarios, muchos de ellos con pocas o nulas interrelaciones. Se habla de

37 Ortiz Garcia, "Comida e Idenlidad. cocina nacional y cocinas regionales en España: Alimentacion y Cullura. Actas del Congreso Internacional Museo Nacional de Antropología, I. La Val de Onsera. Huesca 1999. En el mismo camino esta isabel Gonzalez Turmo, op.cit. Cordoba, 2001 adaptación de unos y otros, también de respuestas de aculturación frente a las tradiciones dominantes. Lo cierto es que en las cocinas regionales, sobre todo en los centros urbanos, es donde se logra percibir de manera más auténtica esta síntesis entre la tradición hispana y la tradición andina (bases de la cocina peruana). En Lima y en otras ciudades del litoral hay una tradición mucho más ligada a la española con una incorporación de productos andinos, así como elementos de otras prácticas culinarias como la oriental, mientras que en el espacio andino hay una tradición de charquis, pachamancas, adobos y picantes, entre otras variedades gastronómicas, que reflejan un paladar especial, diferente del que se puede encontrar en la capita| ${ }^{38}$.

\section{III \\ Construcción de la noción de patrimonio gastronómico en el Perú}

Siempre se ha ponderado el buen comer de los peruanos. La cocina peruana es amplia, basta y compleja. Descansa sobre dos tradiciones: la andina y la hispana. Aportes europeos, africanos y orientales son asumidos en momentos y grados diferentes, sobre todo en lo que a técnicas culinarias compete.

Un posible bosquejo de patrimonio cultural gastronómico que represente a toda la sociedad peruana, ya sea porque él se ha heredado, construido a partir de una situación de grupo hegemónico, o inventado por necesidad de una tradición gastronómica es el que se mostrará a continuación. La pregunta inicial viene por los tipos de gastronomía que se fueron construyendo a lo largo de los siglos coloniales y republicanos en el Perú de acuerdo con los fines, valores, emociones o costumbres de la sociedad ${ }^{39}$.

Este planteamiento parte del encuentro de las dos tradiciones mencionadas asi como

\footnotetext{
38 Antonio Cisneros, op.cit. Lima, 1995 Revisar la colección Cocinas Regionales Peruanas en 5 volümenes, publicada por la Universidad de San Martin de Porres, Lima, 1999.2000.

$39 \mathrm{Max}$ Weber es el inspirador de una aproximacion tipologica al hecho gas tronómico, en tanto hecho cultural. La lectura de Raymond Aron, Introducción a Max Weber, El politico y el cientifico, Alianza, Madrid, 1997, resulta útil en esla empresa.
} 
del producto gastronómico resultante. Es preciso conocer los soportes culinarios y culturales de ambos grupos para establecer lo que de suyo aportó cada uno en este mestizaje.

\section{La cocina prehispánica}

¿Qué cultura culinaria existia en el Perú antes de la llegada de los españoles? La dieta prehispánica descansó en una muy variada producción de recursos alimenticios, consecuencia de un perfeccionado sistema de andenerías y regadio que permitía ocupar tanto las quebradas andinas como los valles. El éxito de esta dieta alimenticia se debió a una serie de factores como el conocimiento de las propiedades de los productos, una amplia disponibilidad de nutrientes esenciales, la preocupación por la "seguridad alimentaria", el acondicionamiento del organismo a los productos cultivados y los hábitos de ingestión de los mismos. Además existía una visión integral de la comida en el contexto de la reciprocidad andina ${ }^{40}$.

Esta diversidad de alimentos, y por tanto la complementariedad de nutrientes, correspondia a productos de los reinos animal, vegetal y mineral. Hubo un gran consumo de pescado, crustáceos, moluscos, aves silvestres y domesticadas, roedores, cérvidos y auquénidos. Asimismo se alimentaban de hortalizas variadas, con preferencia por el yuyo, verduras, sobre todo silvestres, rizomas, tubérculos, cereales, legumbres, frutas, oleaginosas y hierbas como huacatay, muña, chincho o paico, que pudieron servir de condimento para las comidas a la par que el aji y el rocoto.

\footnotetext{
40 Acerca de la alimentación prehispanica los ya citados, Antunez de Mayolo, op cit, Lima, 1981 y Ciro Hurtado, op.cit, Lima, 2000. Una fuente imprescindible para el estudio de la dieta precolombina es la cronica de indias. Para el caso de America hispana en general, Gonzalo Femandez de Oviedo. Sumario de la Nalural Historia de las Indias, Fondo de Cultura Economica, Mexico, 1979, José de Acosia, Histona Nalural y Moral de las Indias. Edición preparada por Edmundo O'Gorman, Fondo de Cultura Economica, México, 1979 y, fundamentalmente, Bernabé Cobo. Histona del Nuevo Mundo. Estudio preliminar y edición de Francisco Maleos, Allas, Madrid, 1964, (BAE XCl). Para el caso peruano, Pedro de Cieza de León, Cronica del Pení Primera Parte, Introducción de Franklin Pease G.Y., Pontificia Universidad Catolica del Perú, Lima, 1984; del mismo autor. Crónica del Peru. Tercera Parte, Edición de Francesca Cantú, PUCP. Lima, 1987; Pedro Pizarro, Relación del Descubrimionto y Conquista de los Reinos del Perú, Edición y Consideraciones Pretiminares de Guiltermo Lohmann, Notas de Pierre Duviols, PUCP, Lima, 1978; Inca Garcilaso de la Vega, Comentarios Reales de los Incas, 2t. Biblioteca Ayacucho, Caracas, 1976, y Felipe Guaman Porna de Ayala, Nueva Corónica y Buen Gobierno, Edición a cargo de Rolena Adorno, Siglo XXI, Mexico, 1980, son de consulta imprescindible.
}

A partir de estos productos se elaboraron potajes siguiendo técnicas culinarias como el horneado en piedras, la pachamanca y la calapurka, o en tierra, la huatia; y la cocción en agua, el mote y la patasca, y en fuego (o tostado), la cancha; en los tres casos sobre la base de maiz. También se consumió el locro, guiso de papas con ají, y una variedad de chupis y lawas o sopas, uchus o guisos picantes y humintas o bollos de maíz tierno. El charqui o carne seca era de lo más representativo, lo mismo que el pan cotidiano al que llamaban tanta.

En cuanto a la bebida, la chicha, fundamentalmente la de jora -puesto que hubo también de otras variedades de maíz, maní, molle, cañihua, quinua, maguey y algarrobo- era el complemento indispensable de las colaciones de mediodía y vespertina, haciendo llevadera la tarea cotidiana. Después de la ingestión de la chicha el individuo se recuperaba del duro trabajo y rápidamente entraba en un estado de plenitud corporal. Se bebía en pequeñas porciones y en grupo, con lo que se subrayaba el sentido colectivo de la alimentación. Es interesante saber que la chicha consumida en un promedio de dos litros diarios proporcionaba por lo menos la tercera parte de las calorías necesarias para el sustento.

Un aspecto sobresaliente es el referido a las técnicas de conservación de alimentos: Se utilizó una cantidad importante de mecanismos de refrigeración, deshidratación, salazón, curado, asado y hervido para mantener el alimento en condiciones óptimas para su consumo en el tiempo y en el espacio, sin perder las propiedades nutritivas y calóricas.

Finalmente, dos aspectos de la alimentación prehispánica, muy engarzados uno con el otro, merecen ser señalados por su significado cultural y la eficacia con que se practicaban. Se trata de la relación de los alimentos con las prácticas médicas por un lado, y con la magia, por el otro. Como muchos otros pueblos, los andinos diferenciaban los productos o su procedencia gracias a los sentidos únicamente, hallando la relación causa-efecto a partir de la observación, experimentación y comprobación para determinar los principios activos de minerales, plantas y animales. Así es como 
lograron un conocimiento avanzado en farmacopea: por ejemplo el uso de la maca para soldados en entrenamiento. Alimento y medicina formaban parte de una sola tradición. Por otro lado, la magia era parte de lo cotidiano para el indigena, constituía el aspecto simbólico de la comida. Ésta era vista como algo divino puesto que permitía el sustento y la vida, de allí su connotación femenina: el maíz, la yuca, otros tubérculos y las frutas son la transformación del cuerpo del hijo de una mujer y el sol de acuerdo con algunas versiones recogidas por los cronistas ${ }^{41}$. La visión mágica del alimento, así como el uso de elementos alucinógenos, o la prohibición del consumo de sal y ají, se hacen más evidentes dentro del contexto ritual que correspondía a los tiempos de fiesta, en donde se rompía con la monotonía alimenticia y era posible un consumo más diversificado, complementado, como en todo banquete, con música, cantos y danzas.

\section{La cocina hispana}

¿Con qué cultura culinaria llegó el español que conquistó estas tierras? La cocina española del siglo XVI se desarrolló dentro de una coyuntura de crisis triguera que afectó a Europa debido a las malas cosechas continuas que obligaron a los mediterráneos a importar masivamente cereales nórdicos y permitir la instalación de ingleses, holandeses y hanseáticos en sus costas, con un comercio especulativo, manejado por los mercaderes y las autoridades de los grandes centros urbanos. Condiciones como la falta de mano de obra por la emigración hacia América o la expulsión de los moriscos, acrecentó el déficit agrícola; además, la inflación de precios por la introducción de los metales preciosos de las colonias, favoreció el enriquecimiento de unos pocos y el empobrecimiento de unos muchos, que sufrieron de verdadera penuria, especialmente los jornaleros y campesinos. El hambre se refleja en la literatura picaresca de la época que presenta la vida de miseria y desesperación que llevaban los campesinos que se veian forzados a inundar ciudades principales como Madrid, Sevilla, Valladolid o Salamanca. Al otro lado del espectro social había una mesa de lujo con abundante alimento, sabroso y atractivo, con derroche de

\footnotetext{
41 Remito a la version recogida por Antonıo de la Calancha, Corónica moratizada del orden de San Agustin en el Perv. Edición de Ignacio Prado Pastor. Lima, 1976.
}

carnes, frutas y vegetales, mientras que aquellos se conformaban con el cereal y, de vez en cuando, con los interiores. Una muy buena parte de los conquistadores, por lo menos la tropa en su conjunto, provenía de esta cultura del hambre ${ }^{42}$.

En ese entonces, como toda cocina del Renacimiento, España presentó una gastronomía suntuaria frente a una cocina popular. En el primer caso esa sapiencia gastronómica se puede rastrear a través de los cocineros cortesanos, y el interés de los monarcas por este conocimiento y la puesta en práctica de las recetas más cotizadas. Nobles, aristócratas y burgueses emergentes disfrutaron de una gastronomía que era producto de una depurada técnica gastronómica, con fusiones entre lo salado y lo dulce, hasta llegar a fórmulas ligeras al estilo de moda: el florentino, con un protagonismo casi único de verduras y salsas variadas. Enfrente de esta cocina que alimenta el estómago y los sentidos apareció la "olla", el plato paradigmático y sustento de los españoles, cual columnas de Hércules, consumido a lo largo y ancho de la península por todos los niveles sociales. Plato histórico, recorre los siglos XVI, XVII y XVIII con holgura, para convertirse en el "puchero" decimonónico, y el más reciente "cocido", madrileño, extremeño o andaluz. Se trataba de un plato campesino, enriquecido de acuerdo con los gustos y posibilidades, bien con carnes, aves, verduras o legumbres secas. Los cocineros reales adecuaron los sabores al paladar aristocrático y encontraron en los pasteles de masa hojaldre el medio culinario para la presentación de este platillo, que luego se popularizaría en toda la nación en forma de "pastelón".

Un aspecto interesante que va a las parejas con la dimensión mágico-terapéutica de la dieta prehispánica es la relación entre la comida y la medicina para el hombre del Renacimiento. El tema ocupaba en España tiempo y no pocos desvelos. Desde el siglo XVI hasta bien entrado el siglo XVIII médicos y tratados filosófico-científicos abordaban el aspecto medicinal de los alimentos, y era de ver el dominio de los cocineros en el campo hipocrático.

\footnotetext{
42 Néstor Lujan, op.cit., Barcelona, 1997 y Manuel Martinez Llopis, op.cit. Madrid, 1989. Asimismo, Femand Braudel, Civilización material, economia y capitalismo. Siglos XV-XVIII. Alianza, Madrid, 1984; del mismo autor, E Mediterráneo y el mundo mediterráneo en la época de Felipe $11,2 \mathrm{l}, 2^{\circ}$ ed. Fondo de Cultura Económica, México, 1976. También Odile Redon et.al. Delicias de la gastronomia medieval, Prólogo de Georges Duby, Anaya \& Mario Muchnik, Madrid, 1996.
} 
Los recetarios europeos incluían como uno de sus principales intereses el del conocimiento de las propiedades preventivas o curativas de los alimentos. Por ejemplo todo el tema del ayuno que fue abordado en la Edad Media como un concepto eclesiástico pasó a convertirse en una expresión científica y médica del hambre en una España en donde era posible la coexistencia de "estudiantes famélicos y ogros cortesanos". Al interior de esta práctica médica el placer era también parte de la cura. Se trataba de devolver al paciente a la vida y para ello habia que proporcionarle salud en forma de placer alimenticio. No se trataba entonces únicamente del conocimiento de hierbas y plantas, sino que también formaba parte de una concepción holística.

En resumen se desarrolló una cultura gastronómica asociada con la nutrición, la buena mesa e inclusive con la glotonería. Esto no debe llamar tanto la atención si consideramos la evidente impronta romana, árabe y judía de la cultura española.

\section{Encuentro de dos tradiciones culinarias}

La política de conquista y colonización de la corona española sobre el Nuevo Mundo planteó la cuestión de la convivencia de dos culturas y por ende de dos culinarias. En un primer momento de contacto entre tipos de alimentación antillana y mediterránea hubo un claro rechazo de los frutos tropicales, salvo el maíz y el cazave. Los españoles añoraban el pan y el vino. Al ser la cocina un hecho cultural es evidente que lo que comían los cristianos, los indigenas y los esclavos que llegaron con los españoles no podia ser de común agrado ni significar lo mismo. Lo comible o bueno para unos no lo era para los otros ${ }^{43}$.

Los productos alimenticios del Viejo Mundo fueron llegando paulatinamente a tierras americanas a medida que los colonizadores se asentaban y adecuaban el territorio, la naturaleza y la población a sus necesidades. Se solicitaba con insistencia el envio de trigo, cebada y viñas, además de animales para reproducción. Hasta que los pedidos fueron

\footnotetext{
43 Xavier Domingo, De la olla al mole. Ediciones Cullura Hispánica, Madrid, 1984; del mismo autor, "La cocina precolombina en España", Janet Long. coord., op.cil., Madrid, 1997: [17]-29.
}

atendidos los europeos tuvieron que acostumbrarse a las viandas americanas, con recelo en un principio, luego con mayor confianza pero nunca con total agrado, sobre todo por parte de los funcionarios y gente de alto nivel social. Hubo una evidente infravaloración de lo americano por tratarse de culturas vistas como inferiores, pero al mismo tiempo no hay que olvidar que el paladar y el olfato mediterráneos no estaban preparado para este consumo. Como en toda formación cultural esta aceptación será consecuencia de un proceso de larga duración. Más tarde productos como el maíz, la papa, el frijol, el tomate y el maní no sólo serán aceptados y saboreados por los europeos sino que se convertirán en ingredientes indispensables de sus propias preparaciones, llegando a enriquecer la gastronomía al otro lado del Atlántico ${ }^{44}$.

Pizarro llega al Perú tras cuatro décadas de establecimiento europeo en América. Esto quiere decir que la cultura gastronómica que trae el trujillano con su gente no es la misma que la de aquel entonces cuando se daban los primeros contactos. Los oficiales, como gente de poder y recursos, se alimentaban básicamente de productos españoles cultivados en estas tierras o traídos del otro lado del "charco" como la especería. Hubo el deseo de reproducir en estas tierras los usos y maneras aristocráticas y cortesanas de la metrópolis. La gente más modesta aprendió a combinar los productos de ultramar con los nativos. Aquí está el germen del mestizaje culinario en donde se combinan los productos y las técnicas, y además se va formando un paladar y un olfato para este consumo en particular ${ }^{15}$.

Hay quienes, como Cisneros, afirman que en la capacidad de aceptación y adaptación está el secreto de este mestizaje culinario ${ }^{46}$.

\footnotetext{
44 Hay aportes realmente valiosos acerca de la cocina en América. Eugenio Pereira Salas, Apuntes para la historia de la cocina chilena, Editorial Universilaria, Santiago, 1977; la producción de José Ralael Lovera es fecunda y de ella la obra ya citada, Caracas, 1998, es la más completa. Revisar también Lucia Rojas de Perdomo. Aportes alimenticios del Viejo al Nuevo Mundo, Voluntad, Bogotà, 1993; Ángel Lora González. "Plantas alimentarias americanas en Europa: La historia de una pérdida de identidad", Antonio Garrido Aranda, comp., op.cit., Córdoba, 2001: 111-128, y Janet Long-Solis, "El tomate: de hierba silvestre de las Américas a denominador común en las cocinas mediterráneas", Antonio Garrido Aranda, comp., op.cit., Huesca, 1995: 215-

235 , entre otros.
45 Conviene revisar el ensayo de Sophie Coe, "Los europeos se encuentran con

la tradición andina", Janet Long, coord., op.cit.. México, 1997: (45).55.
46 Antonio Cisneros, op.cit., Lima, 1995 .
} 
Toca resolver en qué medida y en qué niveles sociales esta capacidad funcionó, y en cuánto tiempo se logró conseguir tal adaptación. Nos recuerda, asimismo, que el español es un pueblo mestizo en donde lo ibero, lo celta, lo griego, lo fenicio, lo latino, lo árabe y lo judío han dejado su impronta. Sin embargo hay un gran común denominador entre ellos que facilitó enormemente la construcción de una cultura alimenticia que fue incorporando paulatinamente aromas, sabores, técnicas, usos y costumbres a lo largo de los siglos: el Mediterráneo. Este caso es distinto, puesto que se encontraron culturas totalmente desconocidas. Al final cada grupo socioeconómico fue adaptando su gusto a los productos y preparados de acuerdo con la capacidad económica para adquirir los ingredientes que los diversos potajes precisaban, el conocimiento de las técnicas y procesos culinarios requeridos, así como las ocasiones en que era posible consumir tal o cual alimento. No era igual la mesa del oficial, funcionario o señor, que la del artesano o del soldado, o la del campesino o el esclavo. Tampoco era lo mismo comer en un medio urbano que en un medio rural.

\section{Culinaria y mestizaje en el Perú colonial}

Entre el último tercio del siglo XVI y a lo largo del siglo XVII, con varias generaciones de criollos, mestizos y mulatos, la sociedad colonial fue construyendo una cultura gastronómica en términos de identidad y distinción en relación con cada uno de los grupos sociales. Hay un primer nivel integrado por funcionarios (civiles y eclesiásticos) españoles y criollos aristocráticos y acomodados, con fuertes lazos con la metrópolis. La mesa de este sector presentaba un conjunto de platillos con un fuerte componente mediterráneo (jamones, embutidos, guisos, adobos y asados, variedad de arroces y cocidos) y, como es de esperar, una presencia nativa aunque sea en poca medida, sobre todo en productos y no tanto en técnicas. No olvidemos que muchos de los ahora señores son descendientes de gente de poca fortuna que en tierras del Quijote no sabian lo que era comer carne y menos aún sabian de especias y conservas; de allí la necesidad de remarcar el presente estatus social. Un segundo grupo conformado por criollos de escasos recursos económicos (soldados, artesanos, empleados) así como mestizos y mulatos, dio origen a lo más parecido a una cocina de consenso, en donde lo mediterráneo, lo andino y lo áricano se dieron la mano de forma natural, como natural fue la convivencia entre la gente de lo que se denomina sector popular. El grado en que lo europeo, lo nativo y lo africano estuvo presente en la dieta cotidiana de esta gente dependió de sus posibilidades económicas y del contexto social en que se movía. Finalmente, la población andina, sometida en su mayoría por la cultura española, continuó con su comida tradicional basada en el maíz, la papa, el ají y el charqui, así como con sus técnicas ancestrales, integrando los productos de fuera, vegetales y animales, en su dieta cotidiana en la medida en que existía mayor cercanía con la población española ${ }^{47}$.

Lo andino estuvo presente en la mesa de los criollos en su calidad de productos aceptados por su capacidad nutritiva y su sabor agradable. Fue una adaptación lenta. El paladar español aprendió a saborearlos y desearlos en su mesa cotidiana; entre los mestizos esta aceptación fue espontánea: estaban hechos para ello. Lo curioso es que a esta comida más bien mestiza que incorpora por igual lo español y lo andino se le denomina comida criolla. También hubo una presencia africana interesante en la formación de esta culinaria, fundamentalmente costeña, que si no era por los productos, sí lo fue por la capacidad de transformarlos en apetitosos manjares.

Esta relación entre comida y comensal se desarrolla dentro de determinados ámbitos, públicos o privados. Se establece una nueva conformación de la población de acuerdo con estos parámetros: no es lo mismo comer en casa que fuera de ella. No es 10 mismo comer en una taberna, una chichería, una picantería,

\footnotetext{
47 Antonio Garrido Aranda señala la necesidad de sintetizar las fuentes documentales que permiten una reconstrucción rigurosa de lo que fue el fenómeno de la alimentación colonial. Configura la relación de repositorios posibles en archivos locales, notariales, judiciales, generales, asi como aquellos provenientes de instituciones privadas o públicas, los libros de cocina y los tratados dietéticos. "Pautas metodológicas para la construcción de una historia de la atimentación satislactoria: el recurso de las fuentes", Gabriela Benavides de Rivero, como., op.cit. (lima 2003): del mismo autor et.al., "Los manipuladores de alimentos en España y América entre los siglos XV y XVIII: los gremios alimentarios y otras normalivas de consumo", Antonio Garrido Aranda, comp., op.cit., Huesca, 1995: [169]-214. En el Perú, lamentablemente, poco o nada se ha hecho por un trabajo en este sentido; se trala de un campo intocado pero no intocable.
} 
dentro de una comunidad indígena o en un galpón de esclavos. Como se cocina en Lima no se cocina en Cuzco, Arequipa, Cajamarca, Ayacucho o Puno. Los estudios sobre cocina regional aportan muchas luces en torno de estas maneras en donde es evidente la primacía del elemento andino y una preferencia por productos foráneos como los interiores y la carne, sobre todo de res y de ovino. La manera en que estos productos se preparan es a partir de los uchus, timpus y chupis tradicionales ${ }^{48}$.

La cocina de convento constituye un aspecto relevante en esta construcción de la gastronomía en el Perú. Se trata de un espacio cultural perfectamente delimitado con normas, usos y costumbres en lo culinario que permite un análisis modélico para entender cómo se crea, recrea y mantiene una cultura gastronómica a través del tiempo. Es interesante la relación terrena y espiritual de la gente de Iglesia frente a los alimentos: pan y vino, pero también carne y chocolate. Lo cierto es que la gente que integraba estas comunidades religiosas aportaba su propia experiencia culinaria y una gastronomía propia de determinado sector social. Ello dio origen a una comida cotidiana pero también festiva para el público que lo requería, pues como bien se sabe la repostería fue impulsada fundamentalmente por las monjas, y los monasterios rivalizaban en dulces, pasteles y conservas. También confeccionaban pan y bollos, y en algunos casos platos principales y hasta servicios enteros pues eran contratados por quienes querían satisfacer su vanidad gastando enormes sumas de dinero en banquetes que ofrecian una gama de manjares y preparados ${ }^{49}$.

\section{El siglo XVIII y el arte de los banquetes borbónicos}

Nuevo siglo y nueva dinastía para el imperio español. La tradición francesa, encar-

\footnotetext{
${ }^{48}$ Es de nolar que muchas de estas orácticas tradicionales se conservan hasta la actualidad. Un trabajo enjundioso es el realizado por Ana de la Torre acerca de estas costumbres alimenticias y su valoración en el universo andino, La mujer campesina y las semillas andinas-Género y el manejo de los recursos genélicos, www fao or

49 Muestras de la manera en que eran consumidos los potajes en estos espa. cios son las que presenta Luis de San Valentin en La cocina de las monjas. Alianza, Madrid, 1997 y La cocina de los monjes, Alianza, Madrid, 1997 Tambièn se puede consullar La cocina de los jesuitas, Portada editorial, Sevilla, 1994 (reedición de la de 1818).
}

nada en los Borbones, ingresará tibiamente en la sociedad colonial, fundamentalmente en los salones virreinales, junto con la moda de las tertulias, y el gusto por la música y la literatura. Al final de las veladas, en donde los criollos hacían gala de su ingenio y competían con los chapetones en afición por el arte y las letras, era costumbre disfrutar de una mesa en donde la culinaria francesa mostraba sus mejores galas, sin que ello significara dejar de lado los potajes y dulces criollos.

Se produce un cambio en las formas de sentarse a la mesa. Las reglas de urbanidad contempladas hasta ese entonces en España y sus colonias, hijas de la tradición renacentista, cambiarán en alguna medida, mucha o poca dependiendo de la cercanía e identificación con lo metropolitano. La cortesía francesa y los tratados de urbanidad adquirirán una mayor presencia al interior de la corte virreinal y las familias aristocráticas; al otro lado, el pueblo seguirá con sus costumbres de siempre, comiendo y festejando a su manera. Las reglas de comportamiento y urbanidad ingresan en el espacio culinario y modifican las maneras de elaboración, conservación, presentación, servicio y consumo de los delicados platillos que se degustan en los banquetes borbónicos. Existe todo un arte de poner la mesa que acompaña en refinamiento al que se produce en el nivel del paladar y el olfato. Esto lleva a que muchos platillos criollos, de evidente raigambre entre los sectores altos de la sociedad, deban reducir el nivel de picante en el preparado, o simplemente tengan que dejarse de lado porque no combinan con el nuevo gusto.

El pueblo criollo y mestizo tiene una culinaria totalmente asumida e identificable. Es un alimento sabroso, contundente, con fundamento, en donde prima la carne, la papa y el ají, sea en estofado, adobado o guiso. Esta comida popular será siempre ponderada por los comensales durante las festividades, tanto en los espacios familiares y privados, como en los públicos, la plaza, la taberna o el café. En el nivel de la culinaria andina, el campesino seguirá los patrones tradicionales de consumo, y las relaciones culturales y simbólicas en torno del alimento no sufrirán mayores cambios, salvo por la carencia de algunos productos debido a problemas de tipo económico, pero no por 
problemas de tipo económico, pero no por trastornos importantes en los usos y costumbres alimenticios $^{50}$.

\section{La cocina republicana}

¿Hubo un cambio sustantivo en la cultura gastronómica peruana como consecuencia de la independencia política de España? No de manera inmediata. Fue incorporando paulatinamente otras tradiciones culinarias aunque siempre manteniendo el aspecto de identidad y distinción sociales: la aristocracia continuó comiendo sus platillos de acuerdo con la moda del momento, es decir la francesa, y el pueblo siguió comiendo los picantes, estofados, chupes y adobos. Lo interesante es que esta comida empieza a ser denominada "comida típica", y lo mismo sucede con la llamada "bebida típica", entiéndase el pisco y la chicha. Estos rótulos corresponden a los pareceres de viajeros, fundamentaimente franceses e ingleses, que recorren el país durante el siglo XIX, y crean una corriente de opinión, algunas veces no tan favorable, con respecto a esta comida popular ${ }^{51}$.

Es de resaltar el aporte de nuevos colectivos europeos que ingresan en el Perú a partir de la declaración de entrada libre de extranjeros hecha por San Martín. Diversos grupos ingresarán en el territorio trayendo una cultura gastronómica que se hará presente en la mesa de los hogares, sobre todo limeños, de manera paulatina, aunque no toda de manera tan acentuada como la francesa y la italiana: la

\footnotetext{
50 Una fuente imprescindible para la investigacion de la cultura gastronómica de esta época es la relación de viajeros. De entre ellos el jesuila Wolfgang Bayer. quien estuvo recorriendo el pais a mediados del XVIII, y entre olras cosas senala lo siguiente: "Los hombres se sientan a la mesa en sillones, pero la dama permanece sentada en su 'estrado' donde so le sirve la mesa con diversos manjares". Asimismo hace una presentación bastante completa de los sislemas culinarios de los diversos grupos sociales, "Viaje por el Perú en 1751 recopilación de Estuardo Núñez, Viajeros alemanes al Perú, UNMSM, Lima, 1969. Otro punto de vista es el que presenta Concolorcorvo. El lazarillo de ciegos caminantes. Desde Buenos Aires hasta Lima, Espasa-Calpe, Buenos Aires. 1946.

51 Revisar Estuardo Núñez, op.cit, Lima, 1969: Alberto Tauro del Pino, recopilador, Viajeros en el Penu republicano, UNMSM, Lima, 1967; Relaciones de Viajeros, Coleccion Documental de la Independencia del Perú. Lima, 1971: Josè Maria Blanco, Diario del viaje del presidente Orbegoso al sur del Peru, T.2., Edicion de Félix Denegri. PUCP-Inslituto Riva Agùero. Lima, 1974. Una fuente bibliográfica sabrosa en comentarios criticos acerca de la sociedad arequipeña y sus costumbres gasironómicas es Flora Tristan, Peregrinaciones de una paria, Cultura Antántica, Lima, 1948; la de Middendorf tampoco es muy halagüeña, El Peni: obsenvaciones y estudios del pais y sus habitantes durante una permanencia de 25 años, 1. 1, UNMSM: Lima, 1973, y Heinrich Wit1, Diario 1824-1890. Un testimonio personal sobre el Pen' del siglo XIX, 1 (1824-1642), Banco Mercantil, Lima, 1992.
}

primera reforzando el gusto aristocrático la segunda de una manera más democrática con unos platillos bien recibidos en cualquier mesa, no importando el nivel social. Además, los italianos con sus tratorías crean el espacio público del restaurante para un disfrute gastronómico que estaba reservado a grupos reducidos. Ahora los cocineros ofrecerán sus especialidades al público que quiera y pueda pagar por ellas $^{52}$. Otro es el caso de la presencia oriental en estas tierras. Los inmigrantes chinos conservaron sus costumbres culinarias e importaron los productos necesarios para la preparación de sus comidas. Esta población estableció las fondas y fue acostumbrando al paladar popular a sus aromas y sabores. Se produce una fusión con lo criollo, es cierto, sobre todo por la incorporación de los productos nativos. Lo contrario se da con la cocina nikkei, que más bien incorpora técnicas culinarias criollas a productos agradables al paladar japonés como pescados y mariscos.

Todas estas tradiciones han recorrido los siglos XIX y XX y llegan hasta la actualidad conservando su naturaleza culinaria y riqueza gastronómica ${ }^{53}$. Es un momento de revalorización de las cocinas criolla y regionales, tanto a través de planteamientos conservadores o puristas, como por aquellos otros más arriesgados, creadores de la "cocina novoandina" o la "cocina fusión". Las comunidades andinas en mayor o menos medida conservan sus tradiciones alimenticias y culinarias. No se puede obviar tampoco la fuerte migración de esta población a las ciudades litorales en las últimas décadas, sobre todo a Lima, a partir de lo cual se ha producido una nueva manera de consumo en el nivel popular al introducirse costumbres y valores propios de los Andes.

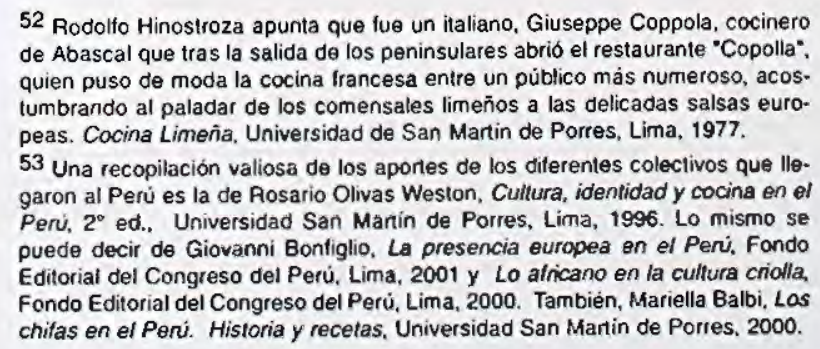




\section{IV \\ Tipología del patrimonio gastronómico}

Cualquier tipología válida para el fenómeno gastronómico debe tener en cuenta los aspectos sociales y culturales que van dando una identidad a los grupos a lo largo del tiempo, permitiendo asimismo una distinción de acuerdo con las posibilidades económicas o determinadas posiciones ideológicas. Paralelamente hay que analizar los elementos relacionados con la posesión o construcción de un gusto frente a los alimentos y las técnicas culinarias, bien sea por herencia, o como consecuencia de factores hegemónicos o manipuladores. Una verdadera integración de lo colectivo con lo individual, las preferencias del grupo y las peculiaridades personales. Todas estas consideraciones, obviamente, no significan de ningún modo un esquema rígido, sino por el contrario, como cualquier hecho cultural, la gastronomía es un ente con dinámica, abierto a ciertas adherencias y separaciones.

En el caso peruano existe un eje vertebral que logra integrar a las diferentes tradiciones gastronómicas y permite que la cocina peruana sea distinguible de cualquier otra cocina. Este punto de conf́luencia entre los diversos colectivos y sectores está conformado por productos que, con diferentes técnicas y bajo diversas presentaciones, constituyen la base de la dieta diaria y se integran en las culturas popular y elitista de formas particulares. Ellos son la carne, la papa, el maiz y el aji; constituyen el "superalimento" 54 . En torno de ellos, se presentan los "acompañamientos frecuentes" como los tubérculos, el arroz, la harina de trigo y los interiores. Luego, los alimentos secundarios, que son aquellos de menor consumo pero conocidos, como pueden ser las verduras, menestras, lácteos, harinas, azúcares, variedades cárnicas y productos de mar. Finalmente, los alimentos periféricos, aquellos que se toman dentro de contextos festivos o especiales y que constituyen lo más cercano a un sello de identidad del grupo. Esta primera constatación no colige la presencia de una gastronomía en común, mas

54 Luis Alberlovargas, op.cut, Mexico, 1997. bien pone en evidencia la riqueza ecológica del Perú. Pero son las técnicas culinarias y sobre todo el paladar de cada grupo lo que permitirá delimitar una tipología gastronómica.

El esbozo de la siguiente tipología se basa pues en categorias geográficas, culturales, sociales y las propiamente gastronómicas, vale decir, de gusto y maneras de comer. Una primera clasificación responde al nivel de las formas de consumo urbano frente al consumo rural. En segundo lugar se establece una distinción entre lo que ha sido la cocina criolla limeña frente a las cocinas criollas y mestizas regionales. En ambos casos se corresponden con el ámbito urbano y alrededores. En cada uno de estos casos se puede determinar, inclusive, una mayor o menor presencia hispana, andina o negra. En el ámbito rural es donde se mantiene con mayor fuerza la tradición prehispánica que equipara en principio el consumo cotidiano de estos pueblos, y en donde las diferencias se evidencian en los momentos de fiesta y celebración ${ }^{\text {ss }}$.

\section{Tradición urbana limeña}

La llamada "comida criolla". En la conformación de esta comida existe la vertiente de productos mediterráneos o que llegaron con los españoles como las carnes, las aves, trigo, caña de azúcar, arroz, los lácteos, verduras, hortalizas, legumbres y frutas, y sobre todo una dupla que le da personalidad: ajo y cebolla. Hay preferencia por platillos como la causa, el escabeche, el anticucho, tortillas y arroces di-

\footnotetext{
55 Las fuentes que se utilizan para este esquema corresponden, además de las arriba citadas, a tecetarios, ta mayoria, modemos. Otro punto de partida, que aunque no se utilice en esta oportunidad es de suma utilidad, corresponde a la fuente periodistica: $\sin$ embargo hay dos publicaciones que serviran cierta. mente al proposito de este trabajo: Federico More, Del buen comer y beber USMP, Lima، 1998, y Adan Felipe Mejia, el corregidor, De la mesa peruana, Edicion de Isabel Alvarez, USMP, Lima. 2002. La colección Cocinas regionales peruanas, $5 \mathrm{t}$., USMP, Lima, 1999-2000 contribuye a definir la construcción de un patrimonio gastronomico en las diversas regiones del pais y permite la comparación por productos y tecnicas culinarias. La recopilación de Josie Sisón Porras, El Perú y sus manjares. Lima. 1994, asi como el recetario de Francisco Graña Aramburu, Mis recetas de cocina criolla pervana, USMP, Lima, 2002, corresponden a una manera de comer en los niveles altos de la sociedad limeña. Finalmente, dos recetarios mas generales: Tony Custer, El ante de la cocina peruana. Ouebecor World Peru. Lima, 1999, y Jorge Stanbury Aguirre, La gran cocina peruana, Bogotá, 1994. Mención aparte, los dulces: las recopilaciones de Gloria Hinostroza Clausen. Pasteleria peruana, USMP, Lima, 2002 y Rosario Olivas Weston, Tralado de dulces y licores de Moquegua, CONCYTEC, 1990. Finalmente señalar como una revista de gastronomia que contribuye en la for mación del sentido patrimonial de la cocina peruana es Carta Blanca, con dos numeros hasta el momento, 1-1 (mayo-junio, 2002) y 1-2 (julio-agosto, 2002).
} 
versos, además de mucho pescado y marisco. De la tradición prehispánica se conserva la cultura del aji, de la papa y otros tubérculos, humitas y carapulca, aunque en ésta lo ancestral es la papa seca

La gastronomia limeña está muy señalada por la española, aunque con una presencia determinante del ají, de la papa y el maiz, los frijoles, el tomate, y por supuesto el pescado. El cebiche, de claro ancestro prehispánico, es un plato mestizo cien por cien.

La comida criolla ha tenido altibajos en su desarrollo, ya se dijo; en la actualidad hay un retorno a esta cocina sabrosa y variada, que se consume en cualquier parte y no sólo en los grandes restaurantes. Puede ser un reconocimiento tardio después de haber alcanzado fama internacional, pero también cabe la posibilidad de ser ahora un simbolo de estatus frente al consumo de la población andina inmigrante que llega dia a dia a la capital. Esto es relativo, también, puesto que esta población se hará rápidamente de los hábitos urbanos "modernos" dejando los alimentos tradicionales por arroz y fideos, por ejemplo. El alimento señala una posición en la sociedad $^{57}$.

En Lima hay una presencia de cocina italiana, suiza, china, nikkei y la llamada "internacional" que ha sido muy aceptada desde que ingresó en el circuito de consumo.

\section{Tradición urbana regional}

El Perú es un verdadero mosaico gastronómico si se trata de hablar de cocinas regionales. Cada una tiene una personalidad; una modalidad cultural que le da sentido, identidad, y la distingue de otra, básicamente por la forma de utilizar los productos, combinarlos, sazonarlos, vale decir por las técnicas culinarias empleadas. En las regiones y al interior de ellas, en las provincias, la distinción social es muy marcada y es fácil delimitar los espacios familiares o particulares de los públicos, y al

\footnotetext{
56 Origen de este preparado es un cuy relleno con papa seca y con piedras calientes El cerdo reemplazo al cuy posteriormente

57 Revisar et trabajo de Siephan Smith y Carolina Trivelli. Consumo urbano de ahmentos andinos tradicionales, Insilitulo de Estudios Peruanos. Lima, 2001
}

mismo tiempo los elitistas y los populares. Son éstos, justamente, los que le dan más carácter a cada región. Un espacio paradigmático es la picantería o chichería, en donde se ofrece la chicha de jora y un conjunto de platillos picantes, en su mayoría. Según Elena Llosa este pequeño restaurante, de origen colonial, es el resultado de la fusión de la culinaria andina con la costumbre hispana del negocio de comida o mesón ${ }^{58}$, sin quitarles su aspecto de chicheria, algo antihigiénico, pero con fundamento, según More, donde se puede sentir "la fuerte emanación pecuaria de los cerdos, gallinas, perros y gorriones... A las chicherías hay que exigirles una limpieza... que sea compatible con su carácter de chichería ${ }^{59}$.

De acuerdo con Rossano Calvo no hace mucho había 500 establecimientos en la ciudad del Cuzco, con jerarquías según "la buena comida y la buena chicha" que se ofrezca, pero en todos los casos, preservando la función social integradora, colectiva y celosa de las tradiciones, al punto de conservar el fogón con leña y el "caporal" para beber la chicha ${ }^{60}$. Estos establecimientos se diferencian de otros llamados quintas, especie de "lugares de descanso" en las afueras de la ciudad, antiguas casonas de hacendados que hoy sirven para el fin culinario. Pero picanterías también existen en Arequipa o Piura, por citar las más conocidas, junto con la cuzqueña. En este caso, en las "chicherías" es posible encontrar gran variedad de chichas y un piqueo cargado de aji; asimismo hay productos muy peculiares como los plátanos en chifles.

En cada región hay lo que se conoce como "comida típica" y responde a las ocasiones en que se le consume: fiestas patronales o populares, ocasiones familiares, o espacios más sencillos como las nombradas picanterias. Las preferencias culinarias también son marcadas según los estratos socioeconómicos. En sintesis se puede afirmar que esta cocina urbana regional representa el mestizaje más claro de productos y técnicas culinarias, en

\footnotetext{
58 Eleana Llosa, Picanterias cusquenas, vitalidad de una Iradición, AMIDEP. TAFOS, Lima, 1992

59 Federico More, op cit. Lima, 1998: 258-261.

60 Rossano Calvo, "La comida tradicional cusqueña contemporanea y sus espo. cialistas", Folktore urbano del Cosqo, Cusco. 1992: [109]-129
} 
donde es posible la pachamanca y la huatia al lado del frito, o las salsas de aji (llatán) compartiendo la mesa con los soufflés. Hay una marcada preferencia por los potajes prehispánicos. enriquecidos con productos como carnes de vacuno, ovino, porcino o aves de corral, y también productos lácteos. No faltan los chupes (sopas), lawas (cremas), timpus (pucheros), patasca (papa, maíz, trigo y carnes de cerdo y res), rokros o ajiacos, ni la cancha, el chuño, el cochayuyo o el mote como acompañantes. El sabor regional descansa, a la par que en la técnica, en el tipo de condimento protagónico: huacatay en el sur, culantro en el norte, paico y muña en el centro, lo mismo que el chincho, sin que esto sea una norma rígida.

Las ciudades del litoral como es obvio tienen un consumo de productos ictiológicos relevante. Asimismo una preferencia por el arroz como acompañante, y en algunos casos como principal. Zona de cultivo, zona de consumo, lógicamente.

\section{Tradición rural}

En el nivel campesino la comida sigue siendo de subsistencia. No ha cambiado demasiado con respecto a lo que fue en tiempos prehispánicos y se ha mantenido desde el siglo $X V I$ hasta la actualidad. Lo que sí es cierto, como se desprende de lo señalado por Antúnez de Mayolo, es la dificultad que el hombre andino encuentra para retomar la relación ancestral con el medio que lo circunda; el daño ecológico ha sido muy grande y, hoy más que nunca, de lo que se trata es de sobrevivir. Se habla de una subalimentación de la población La tradición alimenticia del campesino sigue descansando en el factor nutricional y en los valores de cohesión social e identidad con el medio ambiente. El consumo es sobre todo de papa, maíz, y charqui Complementa la dieta con otros tubérculos, granos y proteinas.

Sin embargo el poblador andino establece relaciones y jerarquias entre los productos, la culinaria y las normas. De acuerdo con ellos se dan las identidades. A esta capacidad de nutrir se agrega la terapéutica: en medio de ambos parámetros se va reconociendo este hombre como individuo y a la vez como miembro del grupo.

De acuerdo con los estudios in situ, se ha llegado a reconocer tres tipos de comida: la ordinaria, la festiva y la ritual ${ }^{61}$. La base de toda la alimentación, cualquiera sea el segmento, es la preocupación por la conservación; la memoria de esa "seguridad alimentaria" de épocas pretéritas permanece muy patente. En el caso de la comida festiva el eje es el timpu y a ello se añade alguna carne (cordero o pollo). Lo más importante es lo simbólico de la ocasión en donde el proveedor de alimentos debe demostrar su capacidad para cumplir con los preceptos de la comunidad; mayor prestigio en la medida en que se satisfaga más el consumo de alimentos. El último nivel refleja que el hombre andino no ha perdido su contacto con el entorno, con el cosmos, con los entes tutelares a quienes "debe alimentar correctamente" para seguir viviendo y alimentándose él mismo.

\section{Conclusión}

No se puede hablar de la construcción de un único patrimonio gastronómico en el Perú. Puede argumentarse a favor de esta hipótesis la demarcación de espacios privados y espacios públicos. Por lo menos hasta los últimos treinta años no es posible que un ciudadano y un campesino se identifiquen en un mismo patrimonio gastronómico: no hay ningún espacio público que los concentre; es más, no debemos sorprendernos ante la idea de que a partir del siglo $X V I$ hasta el siglo $X X$ han coexistido dos grandes espacios públicos: uno occidental $y$ otro andino, cada uno con un patrimonio o herencia que conservar y difundir, y por lo tanto con una identidad que mantener. Hubo contactos, ciertamente, de tipo económico, político y social, pero en el nivel de las representaciones mentales y los valores la cosa no es tan explícita. ¿Se puede establecer el patrimonio gastronómico de la nación peruana en tanto combinación de un producto de la tradición occidental y otro, fruto de la tradición andina?

Puede ser que este fraccionamiento produzca una convivencia natural en donde cada espacio

\footnotetext{
61 Gerardo Fernandez. "El banquete aymara", Revista Andina, $12-1$ (julio 1994).
} 
público posibilite el desarrollo de algún tipo de gastronomía.

Hay que tener cuidado con afirmaciones que señalan que la comida peruana es producto del consenso nacional y aluden a una gastronomia que afirmaria los valores propios de la nación. Habria que empezar por demostrar que existe una sola nación en el Perú y por tanto que todos los compatriotas se reconocen como un colectivo que se identifica plenamente con los valores y representaciones que esta comida connota. Es mucho más objetivo plantear la existencia de un conjunto de realidades, llámense tradiciones regionales o cocinas locales, que han construido una gastronomia particular que responde a sus propias costumbres, valores y representaciones, en donde habrá muchos puntos de coincidencia pero también muchos otros de discrepancia, fundamentalmente por el gusto que cada sector posee por determinados sabores y aromas. Hay preferencias y rechazos; lo importante es el respeto por lo "otro", sabiendo que también forma parte de la cocina peruana.

A propósito de la cocina peruana. Un error constante es que se le confunde con la cocina criolla, como si fueran la misma cosa. No lo son, ciertamente. Más que una demostración de rechazo en este caso es una demostración de ignorancia. Felizmente en los últimos tiempos hay una preocupación por publicar la existencia de otras tradiciones culinarias además de la criolla en el territorio nacional, sobre todo en las denominadas cocinas regionales, cuya revalorización y conocimiento son indispensables para que no se pierda el acervo culinario y gastronómico que ellas conservan.

En ambos casos, tanto al hablar de una gastronomía consensuada como al homologar comida criolla con comida peruana, se produce una invención o manipulación del patrimonio gastronómico, sea por un afán nacionalista mal entendido o por un manejo erróneo de la información.

La comida ha servido para producir identificaciones y distinciones en los niveles geográfico, económico, social e ideológico. En la costa no se come lo mismo que en la sierra o en la selva, como tampoco el mundo agrario es igual al espacio urbano en sus modos y costum- bres de consumo alimenticio. Un contexto mercantil no se iguala a un medio pueblerino en tradición e identificación culinarias. Asimismo, los grupos socioeconómicos no se identifican con los alimentos y preparados de la misma manera. El rico come le que quiere, el pobre lo que puede. A lo largo de la historia se dio una hegemonia por parte de Occidente en el aspecto gastronómico -entre otros- que impuso una manera de comer y una preferencia por determinados productos en detrimento de otros. Esta distinción fue creando un patrimonio gastronómico que respondia a los intereses y gustos de un grupo social exclusivo, perteneciente a un contexto geográfico, también limitado, lo cual llevó a errores como el que se mencionó anteriormente. Lo cierto, al final, es que se debe aprender a convivir en medio de las diferencias aprovechando las coincidencias.

Actualmente se plantea, como ya se dijo, la existencia de una gastronomía nacional. No se puede dejar de ser suspicaz y señalar la construcción de un producto hecho a la medida de la "mirada turística". Si de lo que se trata es de elevar el nivel de la cocina peruana para que el binomio turismo-gastronomia funcione competitivamente en el mercado, bienvenido todo perfeccionamiento de técnicas para mejorar los productos y presentar en los restaurantes y hoteles una variedad de platillos y bebidas peruanos de alto nivel gastronómico. Esto tiene un efecto multiplicador porque mucha gente, propia y ajena, estará en contacto con los potajes preparados por los cocineros especializados. Así surgió realmente la moderna gastronomía europea. En este sentido lo más interesante es la investigación culinaria que se lleva cabo en los últimos tiempos, tanto en el nivel de la comida criolla como en el de las comidas regionales. Es bueno que los cocineros y gourmets encuentren una manera de dar impulso al arte culinario bajo todas sus formas y según las diversas tradiciones que conforman este mosaico cultural que es el Perú.

Gabriela Benavides de Rivero

Instituto de Investigación

Escuela Profesional de Turismo y Hotelería Universidad de San Martín de Porres gabriela@inter.net.pe 